Portland State University

PDXScholar

1979

\title{
An electromyographic comparison of muscle action potentials of adult stutterers during signalled expectancy and non-expectancy to stutter
}

Catherine Ann Miller

Portland State University

Follow this and additional works at: https://pdxscholar.library.pdx.edu/open_access_etds

Part of the Speech Pathology and Audiology Commons Let us know how access to this document benefits you.

\section{Recommended Citation}

Miller, Catherine Ann, "An electromyographic comparison of muscle action potentials of adult stutterers during signalled expectancy and non-expectancy to stutter" (1979). Dissertations and Theses. Paper 2892.

https://doi.org/10.15760/etd.2886

This Thesis is brought to you for free and open access. It has been accepted for inclusion in Dissertations and Theses by an authorized administrator of PDXScholar. Please contact us if we can make this document more accessible: pdxscholar@pdx.edu. 
AN ABSTRACT OF THE THESIS OF Catherine Ann Miller for the Master of Science in Speech Communication, with an emphasis in Speech Pathology/ Audiology, presented October 4, 1979.

Title: An Electromyographic Comparison of Muscle Action Potentials of Adult Stutterers During Signalled Expectancy and Non-Expectancy to Stutter.

APPROVED BY MEMBERS OF THE THESIS COMMITTEE:

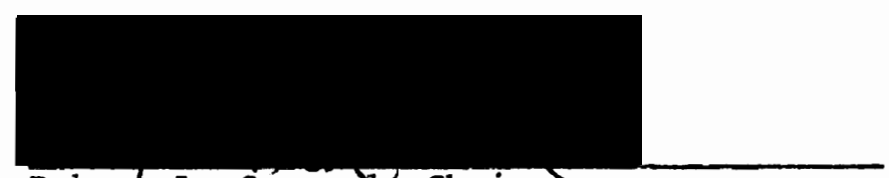

Robert L. CásteeY, Chairmàn

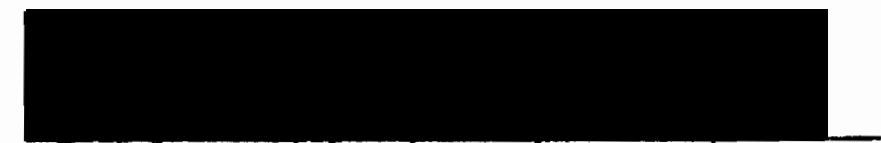

Robert H. English

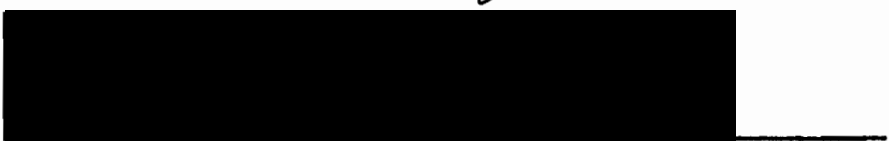

Georgie/H. Hustead

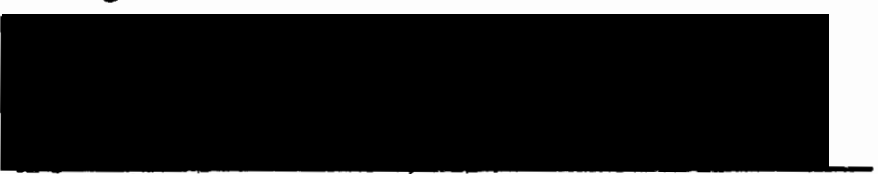

Chadwick Karr

Numerous studies have demonstrated the tension component of stuttering behavior; however, the relationship between muscle tension and the moment of signalled expectancy to stutter has not been investigated. Many theories of stuttering are based on the hypothesis that all moments of stuttering are preceded by expectancy to stutter. It 
also is held by many authorities on stuttering that expectancy is a precipitative, if not causal, factor of stuttering. If such is the case, one might expect to see the moment of signalled expectancy to stutter accompanied by an increase in muscle tension in the speech mechanism.

The purpose of this study was to determine what relationship (if any) exists between signalled expectancy to stutter and a significant increase in muscle action potential in adults as measured by electromyography (EMG).

The question posed in this study was: Is the moment of signalled expectancy to stutter accompanied by a significant increase in muscle tension compared to the moment of signalled non-expectancy to stutter as measured by EMG? In answer to this question, the present study demonstrated no significant increase in muscle tension during signa1led expectancy to stutter.

The subjects in this study included 9 male and 1 female stutterers ranging in age from 22 years to 50 years of age with a mean age of 32 years and 9 months.

This study took place in a $6^{\prime} \times 8^{\prime}$ shielded room containing a Grass electroencephalograph amplifier, Model 6B, with a built-in 8-channel polygraph recorder. Seven of the 8 channels were utilized for this study. Tin, dish-shaped electrodes were placed at 6 sites as follows: orbicularis oris; digastric muscle; slightly above the larynx; trapezius muscle; right earlobe (reference electrode); and center of the forehead (ground electrode). Muscle action potentials (MAPs) were recorded for the first 4 electrode sites. 
Each subject was presented with 50 test words, one at a time. Before saying each word aloud, the subject indicated whether or not he expected to stutter when saying the word by pressing a button once for "yes" and twice for "no." After pressing the button, the subject was signalled to say the word.

Peak-to-peak measurements of muscle action potentials for 10 expectancy responses and 10 non-expectancy responses, selected at random, were taken for each of the subjects at each of the 4 electrode sites. Using a t-test for related variables, 4 t-tests were applied, one to each set of MAP values of expectancy responses and nonexpectancy responses at each electrode site for the group as a whole. Statistical analysis revealed no significant increase in muscle tension during expectancy to stutter as compared to non-expectancy to stutter at the 0.05 leve1 $(p>0.05)$ of confidence. Resultant t-test scores were as follows: orbicularis oris, $\underline{t}=0.607$; digastric muscle, $\underline{t}=0.952$; extrinsic laryngeal muscles, $\underline{t}=0.944$; and trapezius muscle, $\underline{t}=0.331$. At the 0.05 level of confidence $\underline{t}=2.26$ was required for significance.

Further analysis of the data revealed a high correlation of +0.77 between accuracy of prediction and the frequency of stuttering. The more one stuttered, the more accurate he was in predicting his stuttering. Conversely, the less one stuttered, the greater the error of prediction. Those subjects who were most accurate in predicting moments of stuttering stuttered on all or nearly all of their expectancy words. Those who were least accurate in predicting their stuttering expected to stutter much more often than they actually did. 
The relationship between the frequency of stuttering and percentage of expectancy words demonstrated a moderate correlation of +0.65. One possible interpretation is that once one acquires the reputation of being a stutterer, he will expect to stutter more, which may serve to maintain the already present stuttering behavior. The person who stutters less may not be better off than a more severe stutterer as he most likely expects to stutter more often than he does. Johnson (1957) stated stutterers live "lives of quiet desperation."

A low level of correlation $(+0.31)$ between accuracy of prediction and percentage of expectancy words was demonstrated. Frequency of expectancy did not appear to be related to accuracy of predicting stuttering. 
AN ELECTROMYOGRAPHIC COMPARISON OF MUSCLE ACTION POTENTIALS

OF ADULT STUTTERERS DURING SIGNALLED EXPECTANCY

AND NON-EXPECTANCY TO STUTTER

by

CATHERINE ANN MILLER

A thesis submitted in partial fulfillment of the requirements for the degree of

MASTER OF SCIENCE IN SPEECH COMMUNICATION with an emphasis in SPEECH PATHOLOGY/AUDIOLOGY

Portland State University

1979 
TO THE OFFICE OF GRADUATE STUDIES AND RESEARCH:

The members of the Committee approve the thesis of

Catherine Ann Miller presented October 4, 1979.

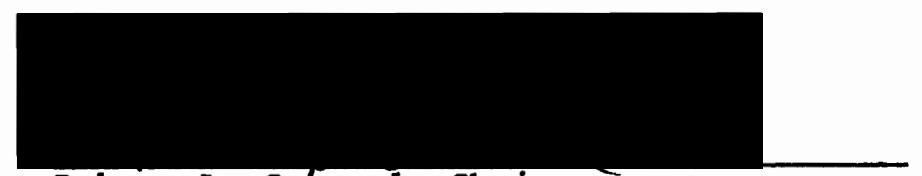

Robert L. Casteel, Chairman
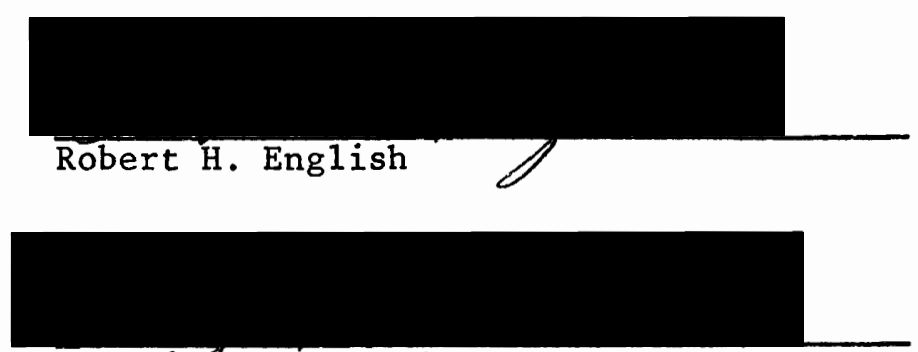

Georgie/H. Hustead

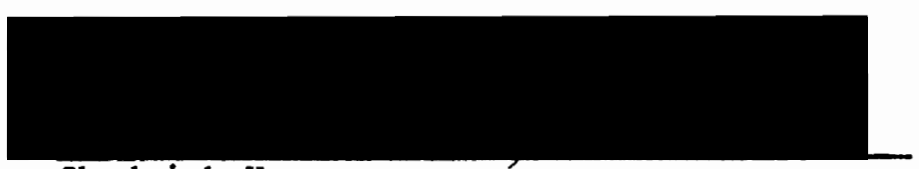

Chadwick Karr

APPROVED :
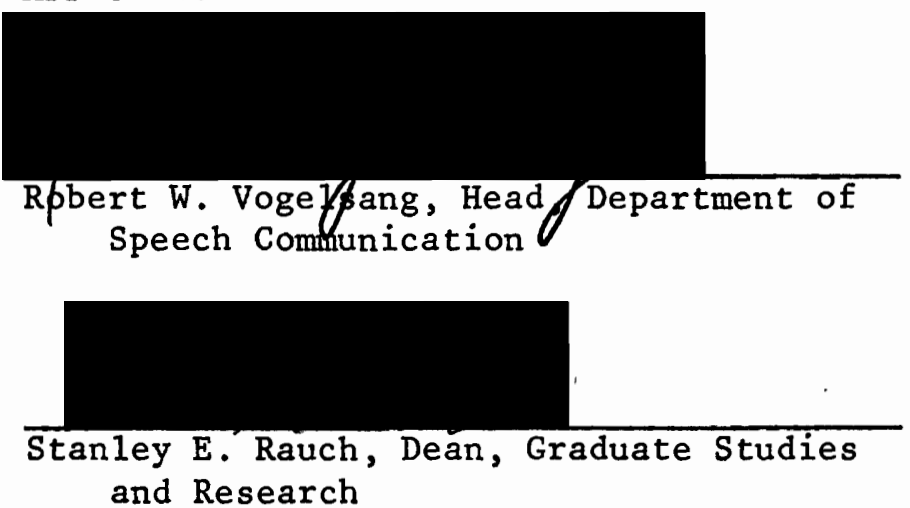


\section{ACKNOWLEDGMENTS}

It is with deep appreciation I acknowledge the generous gifts of time and assistance of the following individuals: Dr. John Roth, M.D., served as an invaluable resource person in the field of neurology and electromyography. Electronic engineers Dave Woody and Larry Mukai custom-made several pieces of equipment used in this study, and Dave assisted in trouble-shooting when the equipment failed to operate properly. My appreciation also goes to Sharon Massey for scheduling appointments for my subjects, and lab technicians Margy Johnson, Colleen Morris, and Teri Strickland for instructing and assisting me in operation of the equipment.

Assisting with the statistical design and analysis of results of this study were Mary Gordon, Dr. Ted Grove, Dr. Jack Hegrenes, and Dr. James Maurer.

Special appreciation goes to those individuals who served on my thesis committee, Dr. Robert Castee1, Dr. Robert English, Georgie Hustead, and Dr. Chadwick Karr. Each of these people gave richly of themselves in time and personal commitment. Thanks for helping me attain one of the major goals in my life.

Finally, my sincere gratitude goes to those who were closest to me throughout the duration of this project. My dear friend Lorelei Peters wondered for two years if she really had a roommate-all she ever heard was typing in the back room. Greatest appreciation and love go to my parents, who, by their example and instruction, instilled 
in me the confidence I could accomplish that which I set out to do. 
TABLE OF CONTENTS

PAGE

ACKNOWLEDGMENTS

iii

LIST OF TABLES

vii

LIST OF FIGURES

viii

CHAPTER

I INTRODUCTION . . . . . . . . . . . . . . 1

Statement of Purpose ........... 3

Definition of Terms ........... . 4

II REVIEW OF THE LITERATURE . . . . . . . . . . 6

Expectancy Theories of Stuttering . . . . . 6

Confirmed and Unconfirmed Expectancy . . . . 9

Expectancy As a Precipitative Factor . . . . . 13

Cues Related to Expectancy . . . . . . . 15

The Consistency Effect . . . . . . . . 21

Summary . . . . . . . . . . . 24

III DESIGN OF THE STUDY . . . . . . . . . . 27

Equipment ............. 27

Subjects ................. . . 31

Pre-Test Procedures ........... . 31

Post-Test Procedures . . . . . . . . 36

Analysis ............ . . . 38 
IV RESULTS AND DISCUSSION . . . . . . . . . . . .

Results . . . . . . . . . . . . . .

Muscle Tension at the Moment of Signalled Expectancy/Non-Expectancy

Accuracy of Predicting Stuttering

Correlation Between Accuracy of Prediction and Frequency of Stuttering

Correlation Between Frequency of Stuttering and Expectancy to Stutter

Correlation Between Accuracy of Predicting

Stuttering and Frequency of Stuttering

Summary . . . . . . . . . . . . . . .

V

SUMMARY AND IMPLICATIONS

Summary • • • . . . • . . . . • • • . .

Implications . . . . . . . . . . . . . .

C1inica 1

Future Research

BIBLIOGRAPHY

A LETTER SENT TO SUBJECTS . . . . . . . . . . . . .

B EXPERIMENTAL PROCEDURE . . . . . . . . . . . . .

C HUMAN SUBJECT RELEASE FORM . . . . . . . . . . . . .

D MAP OF THE UNIVERSITY OF OREGON HEALTH SCIENCES CENTER

E LIST OF STIMULUS WORDS . . . . . . . . . . . . .

F DATA COLLECTION SHEET • . . . . . . . . . . . . .

G ACCURACY OF PREDICTING STUTTERING USING DATA OBTAINED IN PREVIOUS STUDIES 


\section{LIST OF TABLES}

TABLE

PAGE

I Electroencephalograph Specifications. . . . . . . . .

II Values of $t$ and Means Relative to Electrode Site

Between MAP Values During Signalled Expectancy

and Non-Expectancy to Stutter . . . . . . . . . 4

III Frequency of Responses by Category . . . . . . . . . . 44

IV Percentage of Expectancy Words, Words Stuttered, and Accurate Predictions . . . . . . . . . 46 


\section{LIST OF FIGURES}

F IGURE

PAGE

1 Grass electroencephalograph, Mode1 6B.......

2 Surface electrodes ...............

3 Sequence and duration of electronic timer light signals..............

4 Subject's and investigator's event recorders ....

5 Placement of equipment and personnel in shielded room ..............

6 Location of the six electrode sites selected for this study ..............

7 Downward deflection of the subject's event marker . .

8 Electromyograph printout noting the greatest peak-to-peak muscle action potential and electrocardiograph artifacts . . . . . . .

9 Percentage of responses for each category relative to the total number of words presented .....

10 Graph illustrating the correlation between accuracy of prediction and frequency of stuttering . . . . . . . . . . . . .

11 Graph illustrating the correlation between frequency of stuttering and percentage of expectancy words . . . . . . . . . . . .

12 Graph illustrating the correlation between accuracy of predicting stuttering and percentage of words stuttered . . . . . . . . 
CHAPTER - I

INTRODUCTION

Expectancy as a hypothetical construct is the foundation of many theories which purport to explain stuttering (Knott, Johnson, and Webster 1937; Johnson and Millsapps 1937; Bloodstein 1960a, 1961, 1975; Silverman and Williams 1972). Expectancy in this sense involves two basic assumptions: 1) Expectancy has a long-term base, meaning it is founded upon associations with past moments of stuttering or speech difficulty; and 2) expectancy precipitates stuttering. Many studies have yielded evidence which appears to support expectancy as a hypothesis, but they have yet to demonstrate a direct causal relationship between expectancy and stuttering. One of the major problems in the investigation of expectancy is the definition of the term which varies from author to author. The terms "expectation," "anxiety," "anticipation," and "apprehension" are often used interchangeably when in reality one term may mean something quite different than another to some people.

The phenomenon of expectancy appears to exist and must be recognized; however, this investigator questions the validity of basing a complete theory of stuttering on this phenomenon. Luper and Mulder (1964) described four phases of stuttering which are commonly referred to as "incipient," "transitional," "confirmed," and "advanced" stuttering. Only the last two phases, confirmed and advanced stuttering, 
make any mention of conscious anticipation of speech difficulty as being a characteristic of that particular phase. Bloodstein (1960a) stated that in most instances the stutterer appears to be able to predict the occurrence of his interferences. In later writings (1975) he refined this view, stating the ability to predict stuttering becomes very high in adulthood, but there are many exceptions, and accuracy is almost never total in any case. On the contrary, many studies have demonstrated most stutterers fail to predict a majority of their moments of stuttering, and on many occasions they stuttered when they did not expect to do so (Van Riper 1936; Milisen 1938; Martin and Haroldson 1967; Curlee and Perkins 1968; Silverman and Williams 1972; Bloodstein 1975; Wingate 1975). In view of these studies, the assumption that expectancy is a causal factor in stuttering is doubtful; however, expectancy may definitely be a factor which serves to maintain stuttering behavior.

Wingate (1975, p. 41) proposed a means of distinguishing between long-term and short-term expectancy:

Rather than expectancy being thought of as a long-term function having precipitative power, it should be identified as primarily an awareness of immediately impending difficulty in the speaking process. In this sense it is not anticipation but foreknowledge relative to the objective outcome.

Wingate believed the ability to identify the locus of stuttering may be based on physiological cues which most stutterers tend to associate with and focus awareness on sounds or words having a more distinct, perceptual identification. It is true many stutterers respond to certain physiological cues with the expectation they will stutter. On the other hand, some people state that they first expect to stutter 
and then they become aware of physiological cues.

By employing electromyography (EMG) in a study, Guitar (1975)

demonstrated reduction of preutterance muscle activity was linked to a reduction of stuttering, suggesting preutterance behaviors are associated with stuttering. He interpreted his results as supportive of the work of others who viewed stuttering as the result of anticipation of difficulty with speech (Johnson and Knott 1936; Van Riper 1937; and Bloodstein 1961). Bloodstein (1961) noted fear or anxiety is not the direct cause of stuttering so much as is the speaker's anticipation of stuttering. The fundamental assumption of various anticipatorystruggle hypotheses is that all moments of stuttering are preceded by conscious or unconscious expectancy to stutter (Silverman and Williams 1972). Guitar (1975) speculated that abnormal muscle activity prior to stuttering may be a correlate of anticipation, and if certain anticipatory behaviors were reduced, stuttering would likewise be reduced.

\section{Statement of Purpose}

The purpose of this study was to determine what relationship (if any) exists between signalled expectancy to stutter and a significant increase in muscle action potential in adults as measured by electromyography.

The basic question to be answered by this study was:

Is the moment of signalled expectancy to stutter accompanied by a significant increase in muscle tension compared to the moment of signalled non-expectancy to stutter as measured by EMG? 


\section{Definition of Terms}

The terms below are defined as they were used in this study:

Apprehension. Apprehension is to view the future with fear or anxiety with respect to the task of speaking.

Anxiety. Anxiety is an uneasiness of mind resulting from fear of an impending speaking situation.

Anticipation. Anticipation is the act of looking forward in time and visualizing difficulty in a speaking situation.

Electroencephalograph (EEG). An electroencephalograph is an instrument which detects, via electrodes, changes in electrical impulses in the brain and amplifies these impulses so they may be displayed visually on an oscilloscope and/or graph.

Expectancy. Expectancy is to look forward in time and consider probable or certain difficulty in the speaking situation.

Electrocardiograph (EKG). An electrocardiograph is an instrument which detects, via electrodes, changes in electrical impulses in the heart muscle and amplifies these impulses so they may be displayed visually on an oscilloscope and/or graph.

Electromyograph (EMG). An electromyograph is an instrument which detects, via electrodes, changes in electrical impulses created by the firing of muscle fibers in motor units and amplifies these impulses so they may be displayed on an oscilloscope and/or graph. In brief, it provides a visual representation of the action potential of the muscles. EMG also detects electrical impulses which originate in the heart muscle and are conducted throughout the body.

Polygraph. A polygraph is a recording device consisting of two 
or more pens (one per channe1) which record on paper the wave formations created by changes in electrical potential over time.

Channel. A channel is a band of frequencies of electrical impulses transmitted from an electrode through an amplifier to an oscilloscope and/or graph.

Surface electrode. A surface electrode is a small metal disc which is attached to the surface of the skin and used to detect electrical impulses from a single muscle or group of muscles.

Muscle action potential (MAP). Muscle action potential consists of electrical impulses created by changes in muscle tension and monitored by means of electromyography.

Stuttering. Stuttering is an interruption of the forward flow of air for speech due to inappropriate tension in the speech musculature. This speech behavior is characterized by hard glottal attack, repetition, and/or prolongation of a sound or syllable. 


\section{CHAPTER II}

\section{REVIEW OF THE LITERATURE}

The primary concern of the present investigation was to determine what relationship (if any) exists between signalled expectancy to stutter and a significant increase in muscle action potential. In this section the investigator will: 1) briefly review various expectancy theories of stuttering; 2) discuss several studies concerned with confirmed and unconfirmed expectancy; 3) present findings from a number of studies which investigated expectancy as a possible precipitative factor of stuttering; 4) discuss various cues which are often associated with expectancy to stutter; and 5) take a look at the phenomenon called the "consistency effect."

\section{Expectancy Theories of Stuttering}

The meaning of expectancy and equivalent terms such as "anticipation," "apprehension," and "anxiety" varies from author to author, but there exists a common referent. In essence, expectancy is a response to cues representative of past stuttering and is manifested particularly in the form of word and sound fears (Wingate 1975). According to Martin and Haroldson (1967), anticipation or expectation is the referent term for the empirical observation that stutterers can predict, with varying degrees of accuracy, those words on which they will stutter during a reading or speaking task. Expectancy is usually 
thought of as a long-term function having precipitative (if not causa1) power. Wingate, however, believes a more accurate way of looking at stuttering expectancy is to identify it as a foreknowledge, an awareness of immediately impending difficulty. This concept of shortterm expectancy needs to be distinguished from long-term expectancy which is generally associated with cues representing past difficulty. A prevailing concept about stuttering is that it is, as Johnson (Brown et al., 1956, p. 217) defined it, an "anticipatory, apprehensive, hypertonic, avoidance reaction." Various theories derive their origin from this definition, all having the central theme that the person who stutters expects to stutter, and stuttering is viewed as that behavior which is performed to avoid stuttering when an instance of stuttering is expected (Curlee and Perkins 1968). As a result, the more frequently stuttering is expected, the more frequently it occurs (Knott, Johnson, and Webster 1937; Soderberg 1967; Martin and Haroldson 1967; Curlee and Perkins 1968). An implicit assumption of such anticipatorystruggle hypotheses is that expectancy to stutter precedes all moments of stuttering. Such hypotheses also imply expectancy of stuttering is one of the psychological factors related to precipitation of the moment of stuttering (Silverman and Williams 1972).

Bloodstein (1975, p. 8) saw in the consistency effect the very essence of anticipatory struggle reactions. He stated: "It is the outstanding evidence that stuttering is, in principle, a predictable response to stimuli, and at least in large part, a learned form of behavior."

Bloodstein (1975) inferred anticipation on the part of very 
young stutterers from the observation that some of them demonstrated the consistency effect. In making such an inference, Bloodstein departed from the traditional research procedure of simply identifying, describing, and cataloging the phenomena associated with stuttering. He stated even the youngest child may have a basic sense of impending speech difficulty which is not a premonition he will stutter, but simply a vague perception that a part of what he is going to say will be difficult for him to say fluently.

The hypothesis that expectancy occurs not only on a highly conscious level, but also on a low level of consciousness is supported by many studies (Van Riper 1936; Johnson and Sinn 1937; Johnson and Solomon 1937; Bloodstein 1960a, 1961, 1975). Bloodstein (1975) speculated this expectancy, at a low level of consciousness, is a very generalized form which is found in primary and secondary phases of stuttering, and is the germinal form from which the more specific expectations characteristic of the advanced phases of stuttering arise. This subliminal anticipation is inferred from indirect evidence according to Bloodstein. In children who have no conscious expectation to stutter, its existence is revealed by the effectiveness with which distractions eliminate stuttering, by anticipatory devices such as starters and postponements, and by the consistency effect.

Johnson and Ainsworth (1938) felt this expectancy phenomenon was such an integral factor in stuttering they stated that any theory of stuttering which did not include an adequate account of expectancy was inadequate. On the other hand, Wingate (1975) believed if expectancy does underlie the development of stuttering, there should be clear 
evidence of it among children who stutter. Several studies have shown concurrence between expectancy and stuttering is especially poor among children (Milisen 1938; Martin and Haroldson 1967; Silverman and Williams 1972).

\section{Confirmed and Unconfirmed Expectancy}

Many stutterers claim the ability to predict their moments of stuttering with varying degrees of accuracy. This phenomenon of expectancy may be so vivid the person can predict the form and duration of the forthcoming block, or it may be only a vague awareness of impending speech difficulty within the next few moments. Bloodstein (1960a, 1960b, 1975) incorporated expectancy to stutter into his description of phases three and four of stuttering behavior. This conscious awareness is said to be one of the most unpleasant aspects of stuttering. Stutterers frequently report they expect to stutter much more often than they actually do. On the other hand, there are those who say they are unable to predict any moments of stuttering.

In his observations of clinical cases over a number of years, Bloodstein (1960a) claimed as many as 38 percent of 8- and 9-year-olds reported some anticipations. Above this age level, the percentage of cases who reported expectancy to stutter increased until it reached 71 percent for the 16-year-old cases. It is generally agreed there is an increase with age in the percentage of stutterers who report expectancy to stutter (Williams and Silverman 1969).

The intriguing aspect of expectancy is that often stuttering does not occur when the speaker definitely expects it, and conversely, 
moments of stuttering occur when they are least expected. Several studies which set out to investigate the extent to which subjects' expectancy to stutter was accurate in predicting their moments of stuttering will be reviewed in this section.

Knott, Johnson, and Webster (1937) found a high concurrence between expectancy to stutter and subsequent stuttering for 22 adult subjects. Stuttering occurred on 94 to 96 percent of the words on which stuttering was definitely expected, 71 to 79 percent on which stuttering was doubtfully expected, and 0.4 to 3 percent on which no stuttering was expected.

In a study by Johnson and Solomon (1937), 13 adult subjects read 4 passages silently and underlined each word they expected to stutter when reading it orally. The first 2 readings had a 15 -minute interval between marking and reading. The third reading took place after a 1- to 7-day interval, and the fourth reading involved a 15-minute interval as in the first 2 readings. Stuttering occurred on 53 percent of expectancy words and on 10 percent of the non-expectancy words. They concluded expectation functions in relation to the precipitation of stuttering, and that it may operate on a low level of consciousness.

Martin and Haroldson (1967) designed a study in which 22 male and 8 female adult subjects assigned expectancy values to words on a scale from 1 to 5 . "One" signified stuttering was definitely not expected while "5" indicated the subject definitely expected to stutter. After reading a passage silently and scoring each word, each subject read the passage orally 5 times without interruption. There 
was a positive and linear relationship between expectancy value and stuttering, that is, a higher percentage of stuttering occurred on the words assigned higher expectancy values than on words with low expectancy values.

In an attempt to determine how successfully persons could predict their stuttering, Milisen (1938) conducted a study in which 20 male and 4 female subjects, ages 16 to 34 , read 3 passages. For the first reading, the subjects read orally, signalled expectancies, and left out all words which they were not sure they could say without stuttering. For the second reading, the subjects were told to read at their normal pace, pay no attention to anticipation, and stop each time they thought they had stuttered. The third reading was a combination of the first 2 situations where each subject signalled expectancies, then read the word. Each subject was told to stop after each moment of stuttering. Of the expectancy words in Readings II and III, 48 and 85 percent were stuttered respectively. The major conclusion drawn from this study was stutterers were unable to predict some moments of stuttering when the experimenters were sure they were doing their best.

In an effort to prevent expectancy from affecting speech, Johnson and Sinn (1937) had 28 adults read all the words in a passage to obtain a baseline, then on a different day had them read the passage again 1 to 6 times, omitting a11 words on which stuttering was expected. The baseline frequency of stuttering was 8.7 percent. In the subsequent readings, about 98 percent of the stuttering was eliminated by having them read only the words on which stuttering was not 
expected. Johnson and Sinn concluded: 1) There was a strong tendency for expectation of stuttering to occur with reference to words previously stuttered; and 2) words, word characteristics (e.g., number of syllables, initial sound, position in sentence), or stimuli associated with words can serve as cues which precipitate expectancy to stutter. Silverman and Williams (1972) investigated the accuracy of expectancy in predicting stuttering among 84 subjects, ages 8 to 16 . The subjects indicated before reading aloud each of 50 words whether or not they expected to stutter when they said the word. The children between the ages of 8 and 11 years old were able to predict 41 percent of their stuttering, and those between the ages of 12 and 16 years predicted 48 percent of their moments of stuttering. The investigators interpreted these results to mean it is not safe to assume school-age children who stutter can accurately predict stuttering to a common degree, and there was little relationship between accuracy of predicting stuttering and age.

Ten young adult subjects in Wingate's (1975) study read a passage, two word lists, a disordered passage, two nonsense word lists, and a nonsense passage, conditions which supposedly approximated more closely than previous studies the conditions under which expectancy is said to operate. Wingate found expectancy was unconfirmed about twice as often as it was confirmed. Even the confirmed stutterings were inconsistent in that a particular expectancy word was spoken fluently quite often. The frequency of unexpected stuttering, also, was more than twice as high overall as confirmed expectancy. In view of these results, Wingate was not inclined to support expectancy of stuttering 
as a valid hypothetical construct.

This brief overview of studies in the area of predicting stuttering via expectancy should impress upon the reader that there were many various ways in which investigators designed their studies, the methods used to signal and measure expectancy were of a great variety, and interpretations of results were in several instances quite contradictory.

\section{Expectancy As a Precipitative Factor}

Expectancy as a hypothetical construct involves two basic assumptions: 1) Expectancy operates as a function of responses to cues representative of past speech difficulty; and 2) expectancy precipitates (if not causes) moments of stuttering. Bloodstein (1961, p. 81) stated: "Stuttering is not caused directly by fear or anxiety as much as by the stutterer's anticipations, predictions, or preconceptions with regard to speech." In general, the more an adult expects to stutter, the more likely he is to stutter (Milisen 1938; Curlee and Perkins 1968; Seide1, Weinstein, and Bloodstein 1973). It must be remembered the fundamental assumption of various anticipatory-struggle hypotheses is that al1 moments of stuttering are preceded by expectancy to stutter (Silverman and Williams 1972).

Results of Johnson and Solomon's (1937) study indicated a functional relationship between expectancy and precipitation of stuttering. In addition, they concurred with Bloodstein by stating expectation of stuttering does not necessarily operate on a highly conscious leve1. 
Johnson and Sinn (1937) found stuttering usually occurred when the subject was anticipating stuttering on another word ahead of his oral reading. In view of the results, they concluded cues representative of past stuttering were an important factor which served to precipitate stuttering significantly.

Bloodstein (1975, p. 32) stated:

If a word-stimulus representative of past failure has the power to produce a stuttering block, then presumably it is because it evokes an expectation on the stutterer's part that he will have difficulty on it again.

Johnson and Millsapps (1937) conducted a study in which 26 adult stutterers read a 180-word passage 9 times. After the first 3 readings, all words stuttered in any of the 3 readings were blacked out. The subjects read the remaining words in the passage 3 more times. The stuttered words were blacked out again, and the passage was read an additional 3 times. It was found significantly more stuttering occurred in the second and third series of readings on words which were adjacent to previously stuttered words which had been blacked out than on words which were not adjacent to blacked out words. These results supported Johnson and Sinn's (1937) findings and conclusion. When a cue associated with a relatively great amount of past stuttering is introduced into a low stress speaking situation, there is a significant increase in frequency of stuttering. This observation was made in a study by Johnson, Larson, and Knott (1937) in which 10 adults first read orally to the investigator a passage from a cue sheet and then from a control sheet. In the first experiment the cue sheet had a colored border, and the second experiment used only a different text. The subjects then read from the cue sheet in front of an 
audience. Finally, each subject read both sheets to the investigator soon after the audience situation and again 24 hours later. Although the control sheet performance showed a decrease in frequency of stuttering from a pre-audience to post-audience situation of 6.7 percent and 2.9 percent (first and second experiments respectively), there was an increase in stuttering of 20.4 percent for the colored cue sheet and 26.4 percent for the different text cue sheet.

Curlee and Perkins (1968) and Wingate (1975) questioned the validity of the assumption expectancy to stutter is a precipitative or causal factor in stuttering. Curlee and Perkins performed a study in an attempt to gain further insight into the nature of the relationship between signalled expectancy and moments of stuttering. Twelve subjects were divided into three groups. The experimental group experienced shock contingent on signalled expectancies to stutter. The shock-control group received an equal number of shocks but not contingent on signalled expectancies, while the time-control group did not receive any shock. All three groups then underwent extinction procedures under identical baseline procedures. Results showed punishment of expectancy to stutter was associated with a significant decrease in the frequency of both signalled expectancy to stutter and stuttering.

\section{Cues Related To Expectancy}

One of the most important differences between stutterers and normal speakers is the tendency which adult stutterers have of looking ahead in an oral reading or speaking situation and picking out feared words (Milisen 1938). Specific words or sounds may acquire an aura of 
difficulty in several ways. The stutterer, however, primarily remembers certain words which caused severe frustration or penalty when saying them, or he associates frequently used words or sounds with stressful situations. An example of the latter might be saying his name.

As demonstrated in the study by Johnson, Larson, and Knott (1937), words definitely serve as cues representing past speech difficulty. These words, before being associated with a stressful situation, were not considered fear words. After reading them before a large audience, they acquired the same threatening quality as other feared words in the speaker's repertoire. The subjects were found to stutter with much greater frequency on the cue words in the postaudience situation than in the pre-audience situation.

Along this same line, Johnson and Ainsworth (1938) attempted to determine if a stutterer anticipates stuttering with relative consistency on certain words. Sixteen male and 4 female adult subjects read a passage silently and signalled before each expectancy word. The same process was repeated using the same material within 2 to 6 weeks of the first reading. It was found 52 percent of the expectancy words in the second reading were also expectancy words in the first reading. Johnson and Ainsworth concluded expectancy to stutter was a response to words or other cues and was made more consistently to some words than others.

Feared sounds and words vary among stutterers, giving rise to the hypothesis that these specific fears are learned behaviors involving personal experiences of the speaker. Since experiences vary 
between individuals, the cues associated with these experiences also will vary. According to Bloodstein (1960a, 1975), fear of specific words or sounds is a factor peculiar to the individual.

Although expectancy to stutter on specific words appears to be fairly consistent as demonstrated by Johnson and Ainsworth (1938), Wingate (1975) found actual stuttering on feared words was not very consistent. Some feared words or sounds were stuttered; however, many recurrences of these words and sounds were spoken fluently.

The above portion of this section dealt somewhat with words and sounds as they serve as cues of past speech difficulty. The hypothesis that cues precipitate the expectancy to stutter is based on the assumption that expectancy is a long-term process (Wingate 1975). Words and sounds are not the only cues associated with stuttering. Any stimulus which is associated with a stressful situation or speech difficulty has the potential of becoming a cue for expectancy to stutter in the future. In Johnson and Millsapps' (1937) study previously mentioned, black marks on a manuscript served as cues representing past stuttering. Results showed an increase in stuttering on adjacent words to a greater degree than on non-adjacent words.

Another study (Johnson, Larson, and Knott 1937) in which a colored border on the passage sheet served as a cue associated with a stressful situation demonstrated a previously non-expectancy (neutral) stimulus could become a stimulus for expectancy to stutter. As compared to the pre-audience reading, the post-audience reading showed an increase in stuttering of 20.4 percent.

Using data gathered on thirty-one subjects, Brown's (1945) study 
of the loci of stuttering indicated evaluations of words as difficult are associated with linguistic cues, the four major ones being: 1) word length; 2) initial sound; 3) grammatical function; and 4) position in the sentence. Brown stated after the person evaluates a word as being difficult, he then attempts to avoid it by reacting with caution, hesitancy, effort, and conflict, which ultimately results in stuttering behavior. According to Bloodstein (1960a), the stutterer responds in advance to the sound, word, place in the sentence, or any other aspect of the context which serves as a cue.

Wingate (1975) suggests long-term expectancy in terms of word and sound fears represents a distorted perception of factors or cues related to expectancy. He proposed some of the more likely factors to be :

1) Subtle individual differences in the ability to produce certain phonemes in specific phonetic contexts;

2) vulnerability of the system to noise such as might arise under emotional arousal, but from other conditions as well; 3) emotional arousal with perceived effects extending beyond the actual instance of the speech difficulty; 4) remembrance of previous difficulty, with or without emotional arousal at the time; and 5) recollection of certain cues of a physiologic nature in the speech mechanism.

Van Riper (1936) suggested in cases where stuttering was not preceded by a vivid expectancy, serial conditioning had caused the "middle term" (conscious expectancy) to drop out, and the cue itself could be stimulus enough to cause a reaction without any awareness on the speaker's part.

Curlee and Perkins (1968) emphasized the need for further research of variables (which regularly precede a significant number of instances of stuttering) which correlate with expectancy to stutter. 
Cues of a physiologic nature are often associated with expectancy to stutter. Wingate (1975) believed such cues may represent a form of subtle feedback signalling that sequential events in a planning or early formative stage are not proceeding smoothly. He suggested all expectancy is basically of this nature and stutterers tend to shift their focus of awareness to features having a more distinct perceptual identity, primarily sounds and words. Reports by individuals vary as to the physiological cues they experience. One person said he knew when he was going to stutter because his mouth would become tense just before saying the word (Bloodstein, 1960a). The subject with the most confirmed expectancies in Wingate's (1975) study reported her ability to predict stuttering was only approximate and was based on vague cues felt in her throat and mouth. Van Riper (1937, 1971) described certain muscular sets which stutterers take on in anticipation of stuttering.

Brutten (1963) attempted to monitor the relationship between stuttering and the secretion of palmar sweat glands which is considered indicative of anticipatory apprehension. This study involved thirty-three stutterers and thirty-three non-stutterers who were matched for age, sex, and education. The results seemed to indicate the reduction in moments of stuttering and signalled expectancy was related to the decrease in palmar sweat scores. There was no such relationship for normal speakers. The reduction in palmar sweat scores among the stutterers was attributed to a decrease in the anxiety level associated with the stimulus.

Another study (Van Riper, 1936) investigated the change in 
breathing patterns of thirty-seven subjects during expectancy and the moment of stuttering. Van Riper found the variability of breathing during expectancy was much greater than during periods of nonexpectancy.

Bar, Singer, and Feldman (1969) used electromyography with a stutterer and demonstrated expectancy was associated with increased subvocal laryngeal muscle activity.

Guitar (1975) based his study on the hypothesis overt stuttering behavior is preceded by some covert activity which interferes with normal speech. He trained three adult stutterers to monitor and reduce muscle tension at selected points of the speech mechanism before speaking. Elimination of covert preutterance muscle activity resulted in fluent speech. He suggested excessive muscular activity prior to stuttering may be a correlate of anticipation, and if certain anticipatory behaviors were reduced, stuttering also would be reduced.

In an effort to gather evidence in support of the approachavoidance conflict theory of stuttering, Sheehan and Voas (1954) looked at the relative amounts of tension which occur at different stages during the moment of stuttering. Their subjects, 11 males and 1 female, ranged in age from 19 to 40 years. Employing electromyography, they found the point of maximum tension occurs late in the block, near the release, as they predicted would be the case. They interpreted these results as supportive of the approach-avoidance conflict theory in that the increase in tension resulted from the fear-reduction which occurred during the moment of stuttering in order for the release to take place.

As the studies reviewed in this section reveal, there exist 
numerous cues related to expectancy to stutter. Among this varied list were black marks on a script, a text with a colored border, word length, initial sound, grammatical function of a word, sound and word position, and various physiological cues such as dryness of the mouth, palmar sweating, and an increase in muscle tension.

\section{The Consistency Effect}

The consistency effect refers to the tendency for stuttering to recur on the same words in subsequent readings of the same material (Johnson and Knott 1937; Rosso and Adams 1969; Williams and Silverman 1969; Hamre and Wingate 1973; Martin and Haroldson 1967; Stefankiewicz and Bloodstein 1974). According to Stefankiewicz and Bloodstein, the consistency effect in oral reading demonstrates certain features of the reading material operate as stimuli for stuttering. Johnson and Knott (1937) interpreted this phenomenon as a negative reaction to stimuli which occur at specific loci in the speech sequence.

Bloodstein (1960a, 1960b, 1961, 1974, 1975) believed the consistency effect was characteristic to some degree of all stutterers, even those who did not seem to anticipate their stuttering. Bloodstein (1975) went even further to state that in young school-age children, both stuttering and normal disfluencies demonstrated the consistency effect which seemed to be influenced by word length, position of the word in the sentence, grammatical function of the word, and phonetic factors.

Studies by Johnson and Knott (1937) and Johnson and Ainsworth (1938) also supported the view that moments of stuttering occur at 
consistent loci in a non-random order. Brown (1945) concluded lexical words are stuttered more frequently than function words. Soderberg (1967) on the other hand, found function words and.pronouns are stuttered more often than lexical words because function words and pronouns occur more often, and they usually have higher information values. The basic implication of the consistency effect is stuttering does not occur haphazardly; rather, stuttering behavior is a response of varying degrees of predictability to identifiable stimuli or cures.

Hamre and Wingate (1973) noted the frequent concurrence of consistency and reports by stutterers of particular sound or word fears. Their subjects, 13 males and 3 females, ranged in age from 9 to 44. Hamre and Wingate interpreted the traditional concept of the consistency effect as the tendency for stutterers to stutter on essentially the same words in subsequent occurrences, a phenomenon which is explained in terms of word or sound fears, specific word anxiety, and anticipation that certain words or sounds are difficult. They set out to determine if, and to what extent, this consistency effect occurs in various situations which approximate spontaneous speech. Eighteen experimental (stuttered) words and 18 control (fluent) words were taken from a sample of each subject's spontaneous speech. The subjects were then asked to use each word in an initial, medial, and final sentence position. Following this task, each subject read his list of 36 words. The hypothesis tested was that more stuttering would occur on the previously stuttered words than on the fluent words. of the 858 recurrences of the experimental words, 308 were stuttered ( 36 percent), and of the 858 recurrences of the control words, 181 were stuttered 
(21 percent), the difference being statistically significant. Their findings indicated: 1) Stuttering for both experimental and control words was related to sentence position; 2) the incidence of stuttering on both classes of words was much less when they recurred coincidentally than when they were used intentionally; and 3) as word usage became more like spontaneous speech, the frequency of stuttering was lower on particular words; therefore, the validity of inferring the consistency effect in spontaneous speech was questioned.

Williams, Silverman, and Kools (1969) studied the speech of young stutterers and non-stutterers for evidence of the consistency effect. Their results indicated approximately 59 percent of 92 stutterers and 40 percent of 87 non-stutterers exhibited consistency. The investigators did not report what percentage of stutterings constituted evidence of the consistency effect, nor whether the level of consistency was high or low. They speculated on the possibility that a young child's normal disfluencies consist of anticipatory-struggle reactions in the sense that they are based on the child's evaluation of a word, phrase, or sentence as difficult to say, possibly requiring special effort. Following this line of thought, stuttering may not differ from normal disfluencies except in degree.

Two similar studies were performed to determine if, and to what extent, memory of previously stuttered words influenced how those words would be spoken in subsequent readings. In the study by Seidel, Weinstein, and Bloodstein (1973) 2 experiments were set up. Nine males and 5 females, ages 12 to 21 , participated in this study. In experiment I, subjects read the same passage twice with unrelated 
reading material placed between the 2 readings. In experiment II, there was a 2 -week interval between the 2 readings. The results of this study demonstrated a consistency level of nearly 34 percent with the 2-week interval'which was less (but not of statistical significance) than the 40 percent consistency level of 2 successive readings with the unrelated material in between.

In a study conducted by Stefankiewicz and Bloodstein (1974), 15 males and 4 females, ages 14 to 27 , read 2 different passages orally 2 times. One passage was read twice in succession, and the other was read with a 4-week interval between readings. The results showed the mean percentage of consistency to be 62.6 percent for the successive readings as compared to a consistency level of 49.3 percent for the 4-week interva1. The conclusion in this and the previous study was that memory had little influence on consistency; thus, the significant amount of consistency which was exhibited after a 2- and 4-week period must be attributed to learned responses to stimuli. They noted the consistency effect did begin to lessen noticeably with time.

\section{Summary}

In this chapter, 1iterature pertaining to expectancy as it related to stuttering was reviewed. Prevailing theories of expectancy were discussed, several studies concerned with confirmed and unconfirmed expectancy were reviewed, findings from studies which investigated expectancy as a possible precipitative factor in stuttering were presented, cues which are often associated with expectancy to stutter were discussed, and finally, the "consistency effect" as it relates to 
expectancy to stutter was looked at.

Expectancy may be a response to cues representative of past speech difficulty or it may be manifested in the form of word and sound fears. The fundamental assumption of anticipatory-struggle hypotheses is that all moments of stuttering are preceded by the expectancy to stutter. Wendell Johnson (Brown et al., 1956, p. 217) defined stuttering behavior as an "anticipatory, apprehensive, hypertonic, avoidance reaction."

Many studies have investigated the extent to which expectancy is accurate in predicting stuttering. Results vary according to the methods and materials used, design of the study, and statistical analysis. It is generally agreed that stutterers expect to stutter more often than they actually do, and the ability to accurately predict moments of stuttering varies greatly. Several studies indicated expectancy may be one of several interacting precipitative factors of stuttering.

Stutterers often report the experience of fearing certain words or sounds. The words, sounds, and other cues may be associated with past speech difficulty or a particularly stressful or frustrating experience. When the person who stutters evaluates a word or sound as being difficult, he attempts to avoid it which ultimately results in stuttering behavior. Other cues which are related to expectancy include linguistic factors, physiological sensations, and any other type of stimulus which may be associated with past speech difficulty. The consistency effect refers to the tendency for stuttering to recur on the same words as they recur in reading or speaking. Some 
view this effect as evidence the stutterer expects to stutter, and therefore, expectancy is an integral part of stuttering behavior. Studies show the level of consistency varies greatly among individuals as does expectancy, and the consistency effect decays over time for the same reading material. 
CHAPTER III

DESIGN OF THE STUDY

\section{Equipment}

This study took place in a $6^{\prime} \times 8^{\prime}$ shielded room containing a Grass electroencephalograph (EEG) amplifier, Model 6B, with a built-in 8-channel ink-writing polygraph (see Figure 1). The key specifications of this instrument are noted in Table I. EEG equipment also can be used for electromyography as in this study. Seven of the 8 chan-

TABLE I

ELECTROENCEPHALOGRAPH SPECIFICATIONS

Instrument Function

Specification

Sensitivity

Frequency response

Time constant

Noise leve1

Voltage gain (maximum)

Calibration

Warm-up time

Input rejection ratio

Filter

Chart speed
5 Microvolts/millimeter

1 to 70 Hertz

0.12 Second

Less than 3 microvolts

20,000 Microvolts

50 Microvolts, accurate to $\pm 2 \%$

5 Minutes

Not less than 5,000 to 1

60 Hertz

$30 \mathrm{Millimeters/second}$ 
nels were utilized for this study as follows: Channel I monitored muscle action potentials of the lip; channel 2, digastric muscle; channel 3, extrinsic laryngeal muscles; channel 4, trapezius muscle; channel 5, the audio signal from the subject's voice; channel 7 , the investigator's event marker; and channel 8 , the subject's event marker. Channel 6 was not utilized in this study.

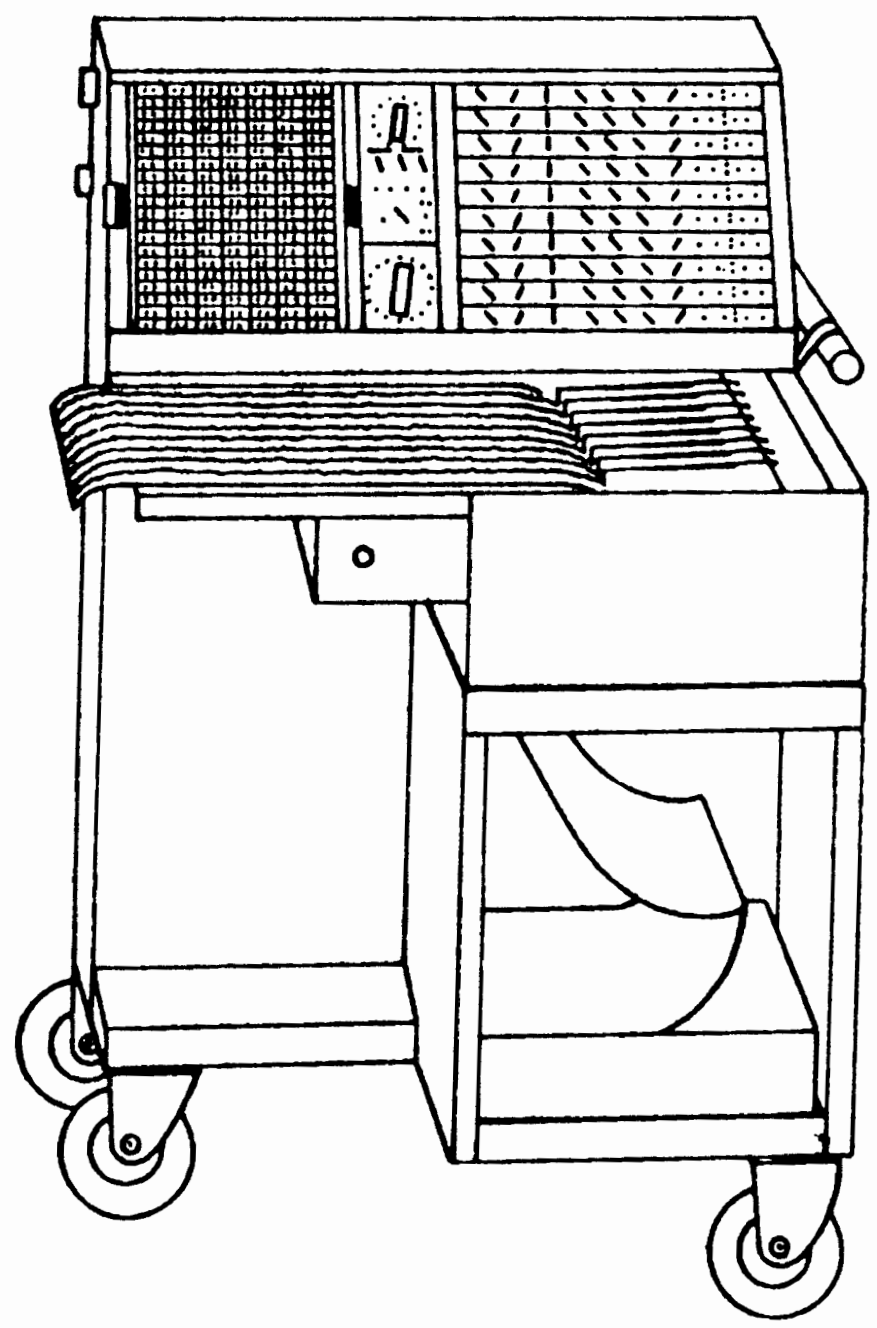

Figure 1. This Grass electroencephalograph, Model 6B, includes control panel console and 8-channel ink-writing polygraph recorder (illustration courtesy of Grass Instru-
ment Co., 1972). 
Tin, dish-shaped surface electrodes, typical of those used to obtain EEGs, were used in this study. These electrodes measured approximately 8 millimeters in diameter and had a small hole in the center of the disc. A small insulated wire was soldered to the outer edge of each electrode. The other end of the wire was fitted with a phone-tip plug which plugged into the electrode board (see Figure 2).

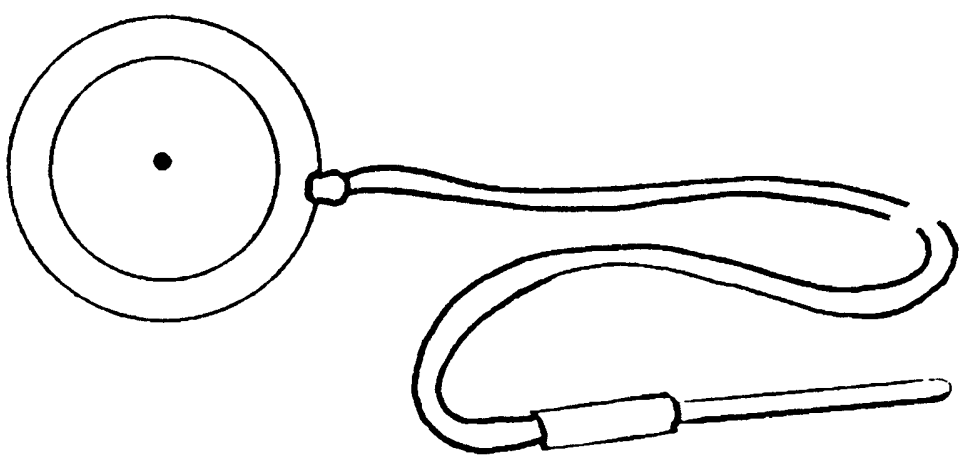

(A)

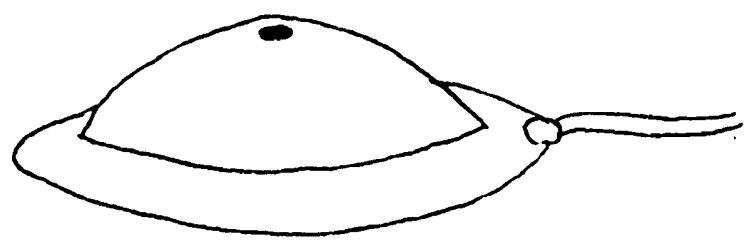

(B)

Figure 2. Typical EEG surface electrodes as those used in this study from (A) a superior view and (B) a side view.

An electronic timer which activated a 1-second light signal at predetermined time intervals of 10 seconds, 3 seconds, and 3 seconds was utilized (see Figure 3 ).

Stimulus words printed on $8 \frac{1}{2} " \mathrm{x} 11$ " white paper were presented in a 3-ring binder which made into an easel when placed on a flat surface. 
A Sony-matic reel-to-reel magnetic tape recorder, Model TC104A, was used to record the subject's verbal responses. Tape speed was 3-3/4" per second, and recording level was set at 7 . Scotch III magnetic recording tape was used.

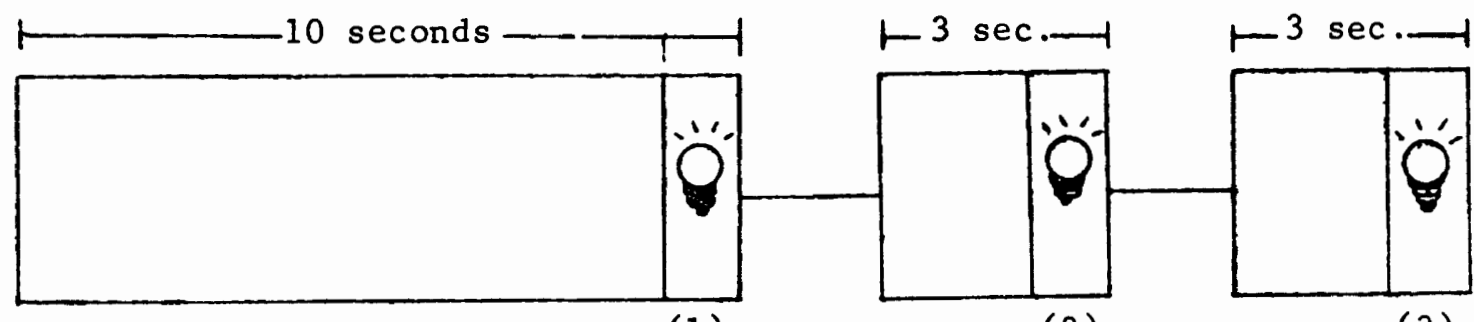

(1)

(2)

(3)

Figure 3. The 1-second 1ight signal occurs at the end of each 10-second, 3-second, and 3-second period of the cycle. (1) The first light signals the investigator to present the next stimulus word to the subject. (2) The second light signals the subject to indicate his expectancy or non-expectancy to stutter by pressing a button. (3) The third light of the cycle signals the subject to say the word.

Two Sony microphones were used in this study. One microphone was coupled to the fifth channel of the polygraph which recorded the audio signal of the subject's voice. The other microphone was used to record the subject's verbal responses on the tape recorder.

Two electronic devices consisting of a casing and a push button served as event recorders. These were coupled to channels 7 and 8 and recorded button-pushing responses of the investigator and subject respectively (see Figure 4 ). 

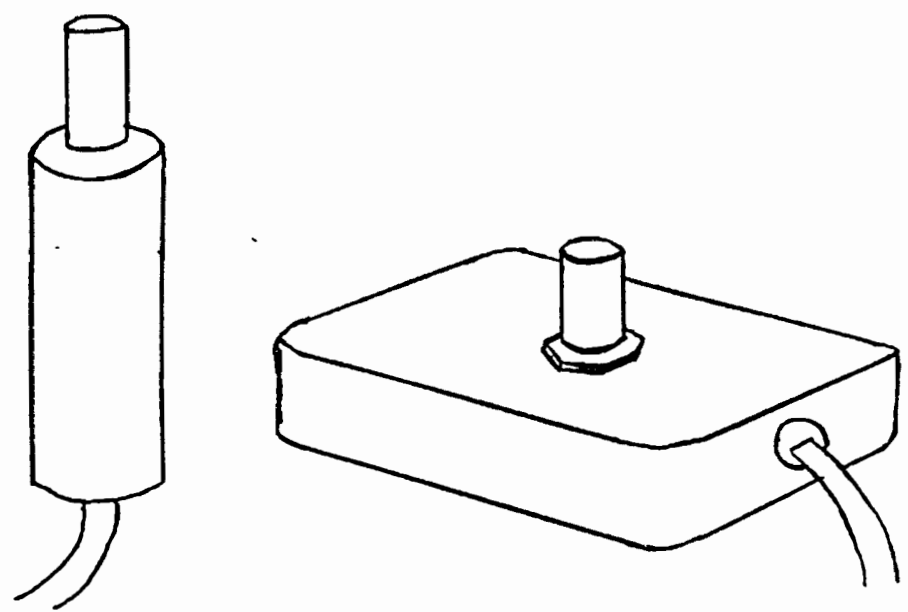

Figure 4. The push button device on the left, which activated the event recorder, was used by the subject to signal expectancy/non-expectancy to stutter while the investigator used the box-shaped device on the right to indicate presentation of a new stimulus word and moments of stuttering.

\section{Subjects}

The subjects used in this study consisted of 9 males and 1 female ranging in age from 21 years and 7 months to 50 years and 6 months with a mean age of 32 years and 9 months. Subjects were obtained through referrals from Portland Center for Hearing and Speech, Portland State University Speech Clinic files, and newspaper advertisements. Subjects demonstrated expectancy to stutter on 20 percent or more of the 50 words presented.

\section{Pre-Test Procedures}

All of the equipment used in the study was set up and in place prior to the arrival of the subject. The electroencephalograph was allowed to warm up for 5 minutes, and channels 1 through 4 were calibrated. 
Each subject was escorted into the testing room by the investigator and seated in a padded, straight-back, armless chair. The subject was positioned so he faced the table on which were placed the stimulus word binder and the electronic timer (see Figure 5).

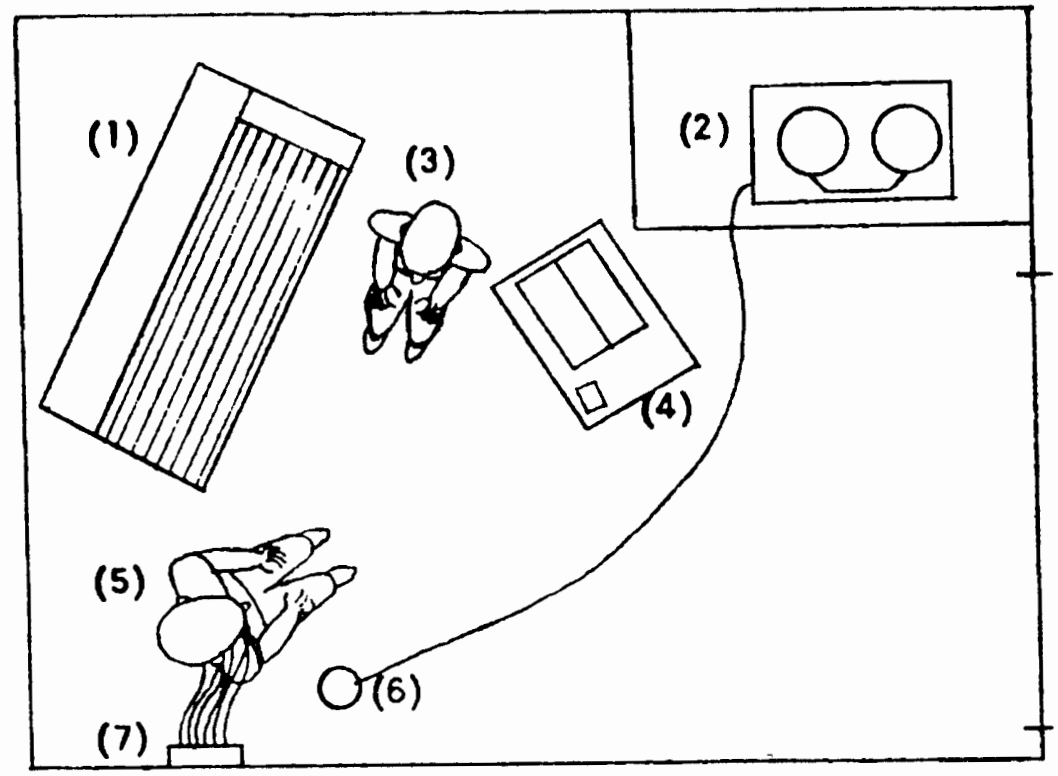

Figure 5. Placement of equipment and personnel in the shielded room is shown above. (1) Grass EEG console and polygraph recorder; (2) Sony tape recorder; (3) investigator; (4) table on which were the electronic timer and three-ring binder of stimulus words; (5) subject;

(6) microphone connected to the tape recorder; and

(7) electrode board into which the electrode wires were plugged.

After being seated in the chair, the subject was instructed in the electrode application procedure. The investigator applied the electrodes in the six predetermined locations. The electrodes were attached with collodian which was applied directly to the outer edge of each electrode. A concentrated blast of air from an air jet caused the collodian to dry quickly. On drying, the collodian secured the electrode to the surface of the skin. 
Four monitoring electrodes, a ground electrode, and a reference electrode were applied to the subject. The electrode sites were determined by pilot studies and were as follows: 1) approximately 0.5 centimeter from the right corner of the orbicularis oris; 2) belly of the digastric muscle approximately 1.0 centimeter to the right of midline and 2.5 centimeters from the inferior ridge of the mandible;

3) at the anterior midline of the neck slightly above the larynx;

4) over the trapezius muscle at the approximate level of the seventh cervical vertebra 2.0 centimeters to the right of the posterior midline; 5) the ground electrode was placed in the midline of the forehead; and 6) the reference electrode was located on the right earlobe (see Figure 6). Guitar (1975) utilized the second and third sites as well as the superior orbicularis oris in training subjects to monitor and reduce muscle tension prior to the act of speaking. Moon (1970) and Lange (1975) used the trapezius muscle site in their studies as an indicator of anxiety. Prosek, Montgomery, Walden, and Schwartz (1978) utilized the earlobe as their reference electrode site. A ground electrode was employed for reduction of extraneous electrical noise detected by the electrodes.

After the electrodes were firmly in place, a very blunt needle was used to abrade the surface of the skin under each electrode, and saline jelly was injected into the hole in each electrode to fill the cavity between the electrode and the skin. The resistance of each electrode was tested using a Grass electrode impedance meter. A reading of 0 to 5 kilohms was considered acceptable. If the resistance factor was above $5 \mathrm{kilohms,} \mathrm{the} \mathrm{skin} \mathrm{under} \mathrm{that} \mathrm{particular} \mathrm{electrode}$ 
was abraded again until the resistance was lowered to the acceptable level. Verification of electrode placement was carried out as described by Hirose (1971).
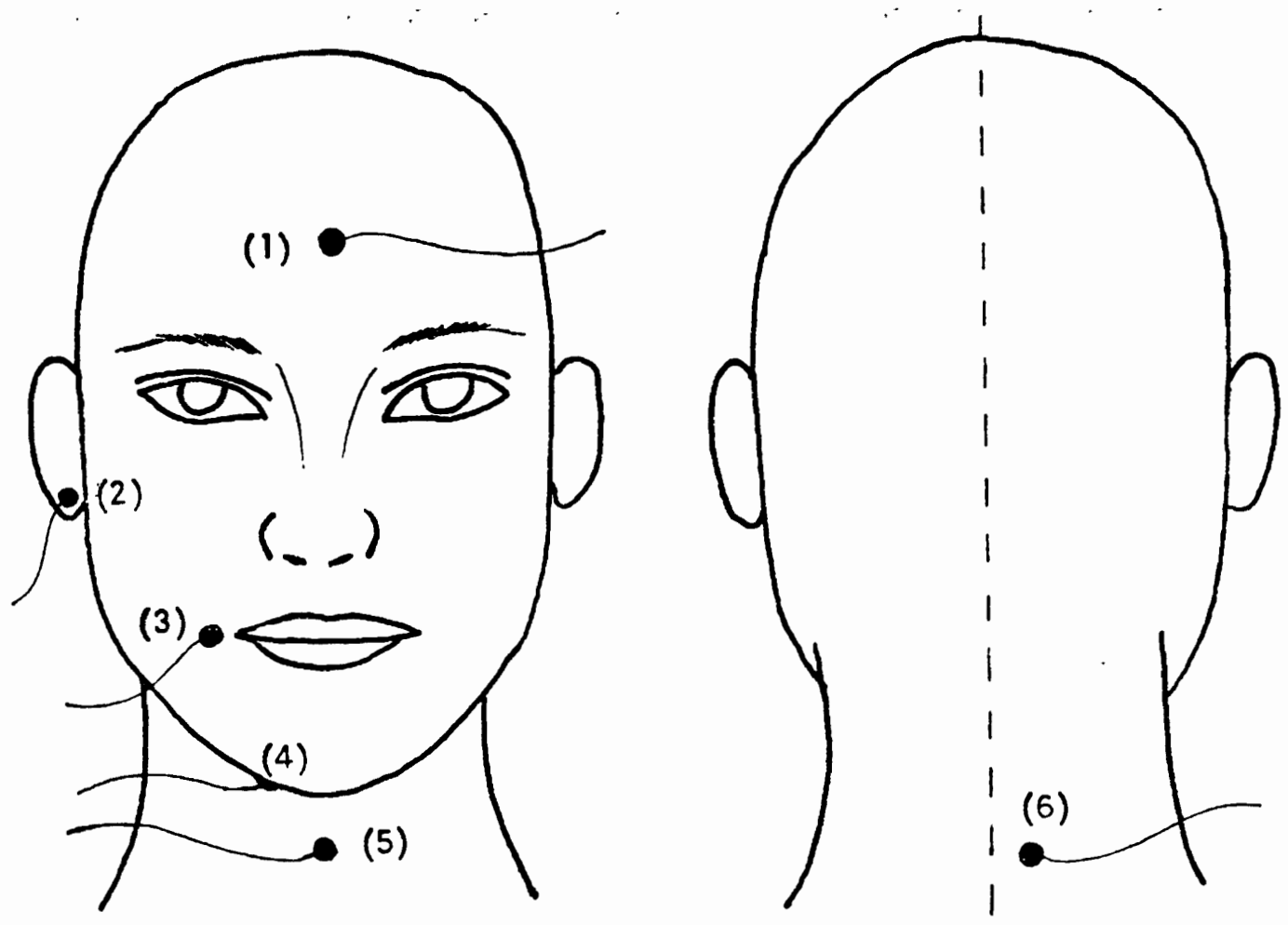

Figure 6. The above illustration shows the location of the six electrode sites selected for this study. They were: (1) forehead; (2) right earlobe; (3) orbicularis oris; (4) digastric muscle; (5) extrinsic laryngeal muscles; and (6) trapezius muscle.

The subject was then instructed by the investigator in the following manner:

For the next two minutes, sit as relaxed as you can. At the end of two minutes I will ask you to press your button once. Then I will ask you to press your button twice. This will be repeated several times. Remain as relaxed as you can.

The subject held the push button device in his left hand during the pre-test procedure and the actual running of the study. 
The 3-ring binder was positioned like an easel and placed on a table approximately 3 feet in front of the subject. The electronic timer was placed to the right of the easel facing the subject. The first light of the interval cycle signalled the investigator to present a word by turning over a page on the binder. The next light signal 3 seconds later signalled the subject to indicate expectancy or non-expectancy to stutter by pressing his event marker button once or twice respectively. Three seconds later, another light signalled the subject to say the word. A 10-second interval occurred, and the light signal cycle was repeated (see Figure 3). A red "swallow" cue card was presented after every third word.

The investigator was seated next to the table on which the binder and electronic timer were placed. The subject was then given the following instructions:

I will present 55 words to you. After looking at a word, you will indicate whether or not you think you will stutter when you say the word. This timer (investigator points to timer) has a series of 3 light signals. On the first light, I turn the page (investigator turns a page). On the second light, you press your button indicating your expectancy to stutter. The third light signals you to say the word.

If you are fairly certain you will stutter when saying the word, press your button once. If you are fairly certain you will not stutter when saying the word, press your button twice. Press once for "yes" and twice for "no." Do not use any management techniques to present stuttering. Swallow only when a red card saying "swallow" is presented (turn to red "swallow" card). The first 5 words will be for practice. Do you have any questions?

The first 5 words presented constituted a trial run and were not counted in the study. Following the trial run, the subject was again asked if he had any questions regarding the procedures. The next 50 
words presented in the above format took approximately 19 minutes to run. The investigator recorded on paper whether or not the subject stuttered by placing a check by those words which were spoken fluently and a dash by those words on which the subject stuttered.

Following the completion of the word presentation, the investigator removed the electrodes by dissolving the collodian with acetone solvent. The subject was thanked for his participation in the study and told the results would be reported to him at a later date. The electroencephalograph was calibrated again on channels 1 through 4 .

\section{Post-Test Procedures}

The recordings from the tape, EMG printout, and the investigator's written recording were compared for consistency and accuracy. Using the tape recording and following along on the EMG printout, the subject's responses were numbered according to the word to which he was responding. His responses were then categorized as follows:

1) expectancy to stutter following by stuttering; 2) expectancy to stutter followed by no stuttering; 3 ) no expectancy to stutter followed by stuttering; and 4) no expectancy to stutter followed by no stuttering.

The two collapsed categories utilized for analyzing the data were: 1) expectancy-those responses on which the subject indicated he was fairly certain he would stutter when saying the word; and 2) non-expectancy-those responses on which the subject indicated he was fairly certain he would not stutter when saying the word. 
were measured in the following manner. A time frame of one second beginning at the moment of downward pen deflection of the subject's event marker was used (see Figure 7).

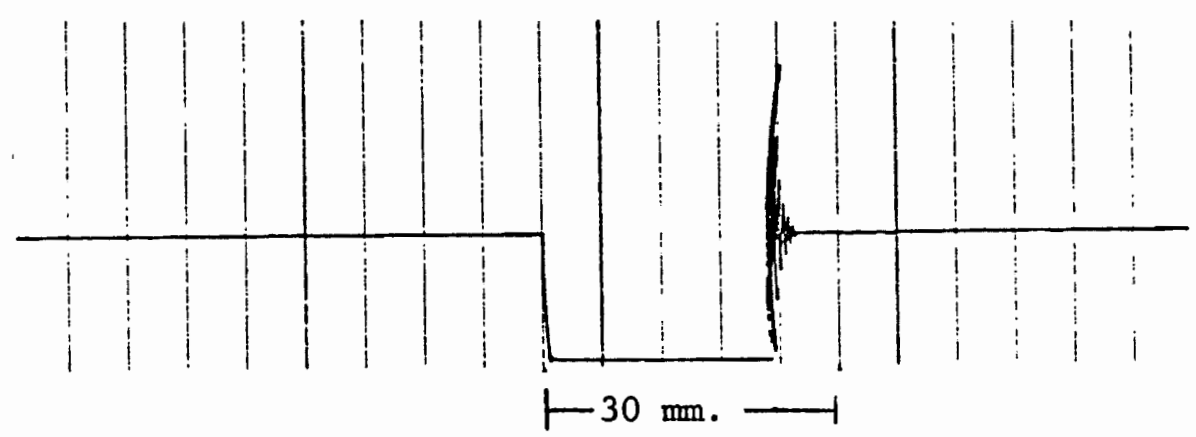

Figure 7. The downward deflection of the pen marks the beginning of the 1-second time frame during which the MAP's were measured. Since the speed of the paper was 30 millimeters per second, the 1 -second time frame measured a length of 30 millimeters.

After the 1-second time frame was marked on the EMG printout, the greatest MAP recorded on each channel within the 1-second time frame was measured. The greatest MAP was indicated by the greatest pen deflection from peak-to-peak (see Figure 8). This method of peakto-peak measurement was utilized in studies by Guitar (1975), Daniel and Guitar (1978), and McLean (1978). Only 10 expectancy responses and 10 non-expectancy responses out of the total 50 responses were measured in the above manner for each subject. These 20 responses were selected randomly for analysis. When measuring the MAP's, the investigator took precautions to conceal information regarding whether the response was during expectancy or non-expectancy to stutter so as not to bias the data. Ten percent of the selected responses were remeasured, and 88 percent of the responses were found to be within 0.25 millimeters of the first measurement. 


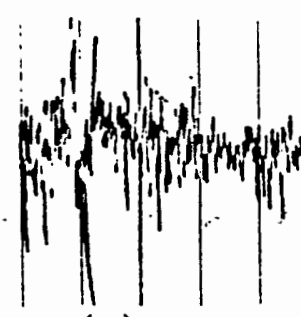

(B)

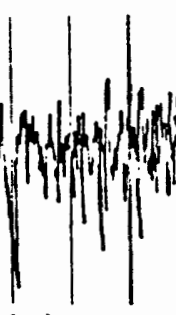

(B)

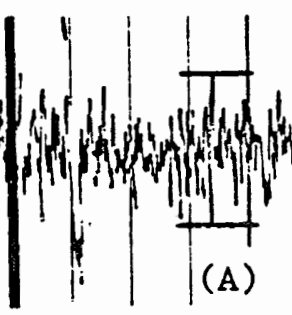

(B)

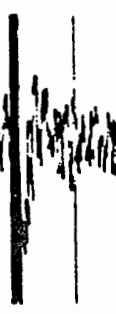

(B)

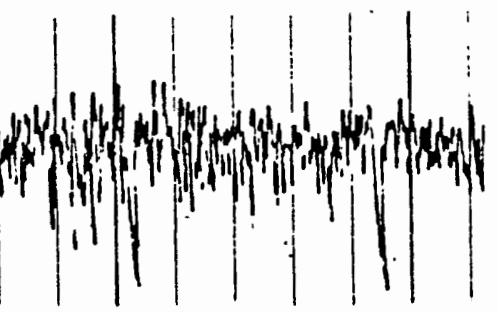

(B)

(B)

Figure 8. The 2 heavy vertical lines designate a 1 -second time frame on the above EMG printout. The greatest MAP (A) in this 1 -second period is marked by 2 horizontal lines. The great pen deflections identified (B) are EKG artifacts. The peak-to-peak measurements in millimeters were converted to microvolts with 1 millimeter representing 5 microvolts. Chart speed was 30 millimeters per second.

\section{Analysis}

The data were analyzed using a $\underline{t}$-test for related variables. Pearson's product-moment coefficient of correlation method was applied to the $\mathrm{Z}$-scores of the raw data to determine correlations for frequency of stuttering, frequency of expectancy, and accuracy of predicting stuttering. 


\section{CHAPTER IV}

\section{RESULTS AND DISCUSSION}

The results of the present study will be discussed relative to the question posed, the statistical procedure and descriptive analysis applied to the data, and the results produced. The interpretations of these results are discussed in a separate subsection of this chapter.

\section{$\underline{\text { Results }}$}

Is the moment of signalled expectancy to stutter accompanied by a significant increase in muscle tension compared to the moment of signalled non-expectancy to stutter as measured by EMG?

The data were analyzed using a t-test for related variables. Four $\underline{t}$-tests were applied, one to each set of muscle action potential (MAP) values of expectancy responses and non-expectancy responses at each electrode site for the group as a whole. Thus, for each electrode site, $100 \mathrm{MAP}$ values for expectancy responses and $100 \mathrm{MAP}$ values for non-expectancy responses were analyzed.

Statistical analysis revealed no significant increase in muscle tension during expectancy to stutter as compared to non-expectancy to stutter at the 0.05 level $(p>0.05)$ of confidence. Resultant $\underline{t}$-test scores for the four electrode sites were as follows: orbicularis oris, $\underline{t}=0.607$; digastric muscle, $\underline{t}=0.952$; extrinsic 1aryngea 1 muscles, $\underline{t}=0.944$; and upper trapezius muscle, $\underline{t}=0.331$ (see Table 
II). At the 0.05 level of confidence $\underline{t}=2.26$ was required for significance.

Muscle Tension at the Moment of Signalled Expectancy/Non-Expectancy

The results of this study, which addressed the basic question, indicated signalled expectancy to stutter was not accompanied by a significant increase in muscle tension compared to the moment of signalled non-expectancy to stutter as measured on electromyography using surface electrodes.

Of particular interest was the electrode site of the upper trapezius muscle which is a good muscle indicator of anxiety-produced tension (Roth 1978). According to the results, expectancy to stutter did not result in an increase in the anxiety level of the stutterer such that the upper trapezius muscle demonstrated a significant increase in muscle tension.

The other three electrode sites corresponded with speech articulators involved in the interruption of the forward flow of air when a person stutters. These sites at which the airflow can be interrupted are the glottis, the lips, and tongue to palate/alveolar ridge. The electrode placed over the extrinsic laryngeal muscles monitored activity of the glottis, the lip activity was monitored by the electrode placed at the corner of the mouth, and the digastric muscle was selected as the site for monitoring the activity of the tongue. The t-test scores for the laryngeal muscles, orbicularis oris, and digastric muscle indicated no significant increase in muscle tension during moments of expectancy to stutter as compared to moments of nonexpectancy to stutter. 


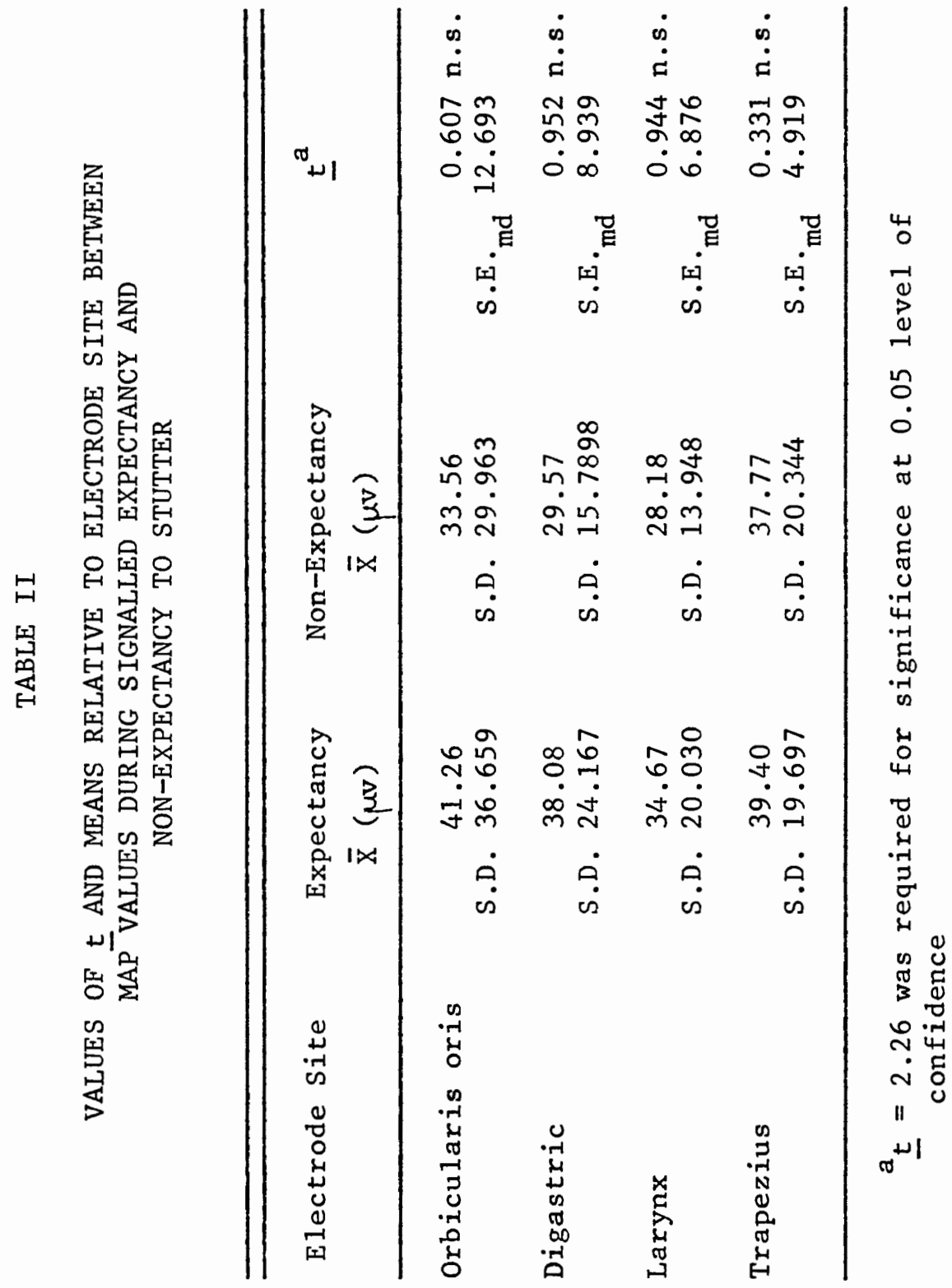


The fact that these muscles did not exhibit a significant increase in tension at the moment of signalled expectancy would lead one to conclude expectancy to stutter does not cause or precipitate stuttering as proponents of the anticipatory-struggle hypothesis purport (Knott, Johnson, and Webster 1937; Johnson and Millsapps 1937; Bloodstein 1960a, 1961, 1975; Silverman and Williams 1972). This hypothesis states all moments of stuttering are preceded by expectancy to stutter.

Several studies using EMG demonstrated an excessive muscular tension component during the moment of stuttering. Sheehan and Voas' study (1954) revealed the point of maximum tension to be late in the "block," near the release. Williams (1955) compared fluent and stuttered speech of stuttering subjects with fluent and "faked stuttering" of normal speakers. His results, indicated there is no evidence that stutterers and non-stutterers are neurophysiologically different. The difference which was seen when comparing fluent and stuttered speech of both normal and stuttering subjects was an increase in muscular tension beyond that characteristic of normal speech during moments of stuttering. Investigation of laryngeal muscle activity during stuttering by Freeman and Ushijima (1978) revealed muscle action potentials higher than those recorded during normal phonation. Additionally, they found the normal pattern of reciprocity of contraction of the laryngeal adductor and laryngeal abductor muscles to be disrupted by cocontraction of these muscles when the subject stuttered. Fina1Iy, Guitar (1975) demonstrated that subjects were able to decrease stuttering by means of EMG feedback of preutterance muscle activity. 
The results of the above studies demonstrated a muscular tension component of stuttering. The present study found no significant relationship between expectancy to stutter and an increase in muscle tension at the time of signalled expectancy; thus, expectancy was not a good indicator of subsequent stuttering with this amount ( 3 seconds) of delay.

Accuracy of Predicting Stuttering

Additional findings in the present study conflicted with findings in previous studies (Johnson, Larson, and Knott 1937; Johnson and Sinn 1937; Johnson and Solomon 1937; Johnson and Millsapps 1937; Johnson and Ainsworth 1938) concerning accuracy of predicting stuttering. These early studies provided the theoretical framework upon which many assumptions concerning stuttering are based. One of those assumptions is that all moments of stuttering are preceded by expectancy to stutter. The findings in the present study do not support this assumption.

Table III shows the frequency of responses for each response category. The totals for the entire group of subjects were: expectancy to stutter followed by stuttering (ES), 122 (24.4 percent); expectancy to stutter followed by no stuttering (E\$), 77 (15.4 percent); no expectancy to stutter followed by stuttering ( $\mathbb{H} S), 46$ (9.2 percent); and no expectancy to stutter followed by no stuttering ( $\$ \$)$, 255 ( 51.0 percent). The total number of responses was 500 . Silverman and Williams (1972) also categorized their subjects' responses into these four categories; however, their focus of interest was the responses which were stuttered and the percentage of those 
TABLE III

FREQUENCY OF RESPONSES BY CATEGORY

\begin{tabular}{crrrr}
\hline \hline Subject & $E S^{\mathrm{a}}$ & $E^{\mathrm{b}}$ & $\mathrm{HS}^{\mathrm{c}}$ & $\mathbb{E \phi ^ { \mathrm { d } }}$ \\
\hline 1 & 1 & 9 & 0 & 40 \\
2 & 9 & 2 & 1 & 38 \\
3 & 12 & 12 & 5 & 21 \\
4 & 22 & 0 & 9 & 19 \\
5 & 33 & 0 & 4 & 13 \\
6 & 6 & 14 & 2 & 28 \\
7 & 13 & 3 & 7 & 27 \\
8 & 8 & 4 & 9 & 29 \\
9 & 6 & 17 & 0 & 27 \\
10 & 12 & $\underline{16}$ & 9 & 13 \\
Total & 122 & 77 & 46 & 255 \\
\hline
\end{tabular}

$a_{E S}$ : Expectancy to stutter followed by stuttering

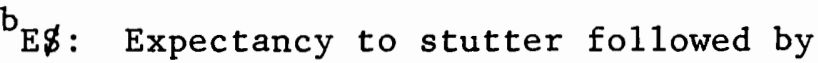
no stuttering

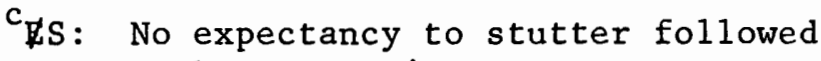
by stuttering

$\mathrm{d}_{\text {ES: }}$ No expectancy to stutter followed by no stuttering

which were correctly predicted. In contrast, the present study looked at the percentage of total responses which fell into each of the four response categories. In addition, the present study calculated accuracy of predicting stuttering using the ES, E\$, and $Z S$ responses, 
whereas, past studies used only the ES and E\$ or the ES and $\mathbb{Z}$ responses, calculating the percentage of correct predictions relative to the sum of the two categories and giving no indication of the percentage of the total number of words presented.

Figure 9 shows the percentage of responses for each category in relation to the total number of words presented in this study. Nearly half of the responses fell into the ES, E\$, or $\mathbb{L}$ category (49 percent). For these 3 categories, 49 percent is a high level of occurrence compared to past studies in which such responses accounted for only 4 to 30 percent of all responses. One explanation for this might be that subjects used in the present study were selected on the basis of frequency of expectancy to stutter. The criterion used was at least 20 percent frequency of expectancy responses. Due to this factor, the overall total of responses may have been biased in the direction of expectancy categories. This, however, should not affect the ratio of correct to incorrect predictions relative to these 3 response categories.

\begin{tabular}{|c|c|}
\hline S & $\$$ \\
\hline 24.4 & 15.4 \\
\hline 9.2 & 51.0 \\
\hline
\end{tabular}

Figure 9. The grid above shows the percentage of responses for each of the four categories in relation to the total number of words presented.

Calculating accuracy of prediction using the ES, E\$, and $\mathbb{Z}$ responses, Table IV displays the percentage of accurate predictions 
TABLE IV

PERCENTAGE OF EXPECTANCY WORDS, WORDS STUTTERED,

AND ACCURATE PREDICTIONS

\begin{tabular}{cccc}
\hline \hline Subject & $\begin{array}{c}\text { No. Words } \\
\text { Stuttered }\end{array}$ & $\begin{array}{c}\text { No. Expectancy } \\
\text { Words }^{b}\end{array}$ & $\begin{array}{c}\text { \% Accurate } \\
\text { Predictions }\end{array}$ \\
\hline 1 & 1 & 10 & 10 \\
2 & 10 & 11 & 75 \\
3 & 17 & 24 & 41 \\
4 & 31 & 22 & 71 \\
5 & 37 & 33 & 89 \\
6 & 8 & 20 & 27 \\
7 & 20 & 16 & 56 \\
8 & 17 & 12 & 38 \\
9 & 6 & 23 & 26 \\
10 & 21 & 28 & 32 \\
\hline
\end{tabular}

${ }^{a}$ Number of ES and $\mathbb{E}$ S responses of total number of responses $(50)$.

${ }^{b}$ Number of ES and E\$ responses of total number of responses $(50)$.

${ }^{c}$ Percentage of ES responses of total number of $E S, E \not$, and $\not S$ responses.

for each of the ten subjects. The unique feature of this method of computing accuracy of predicting stuttering is that all stuttered responses and all expectancy responses are taken into account, whereas, past studies considered all expectancy responses only or all stuttered responses only. By doing this, they were disregarding a substantial amount of data which had serious implications for any 
expectancy hypothesis. Using the data provided in these past studies (Johnson and Solomon 1937; Knott, Johnson, and Webster 1937; Martin and Haroldson 1967; Silverman and Williams 1972), this investigator calculated the level of accuracy of predictions using the same method applied to the data in the present study. These new figures also support the finding that accuracy of predicting stuttering is quite poor. These data are reported in ranges as some of the studies utilized subgroups and some varied the test conditions for the same group of subjects. Levels of accuracy of prediction ranged from 24 to 39 percent (Johnson and Solomon 1937); 79 to 89 percent (Knott, Johnson, and Webster 1937); 27 to 53 percent (Silverman and Williams 1972); and 11 to 23 percent (Martin and Haroldson 1967). The diagrams showing the overall percentage of responses for each category for these studies and the level of accuracy as calculated in the present study are found in Appendix G. Again, overall accuracy of predicting stuttering in the present study was 49 percent with a range from 10 to 89 percent for individual subjects. As was demonstrated by the studies above, accuracy of predicting stuttering is poor.

Overall, the ratio of accurate predictions to inaccurate predictions of stuttering was 122 to 123 respectively, or 49 percent accurate. As these results indicate, the level of accuracy for this group was approximately equal to that of chance.

Correlation Between Accuracy of Prediction and Frequency of Stuttering

Using Pearson's product-moment coefficient of correlation method, Figure 10 illustrates the high correlation $(+0.77)$ between 


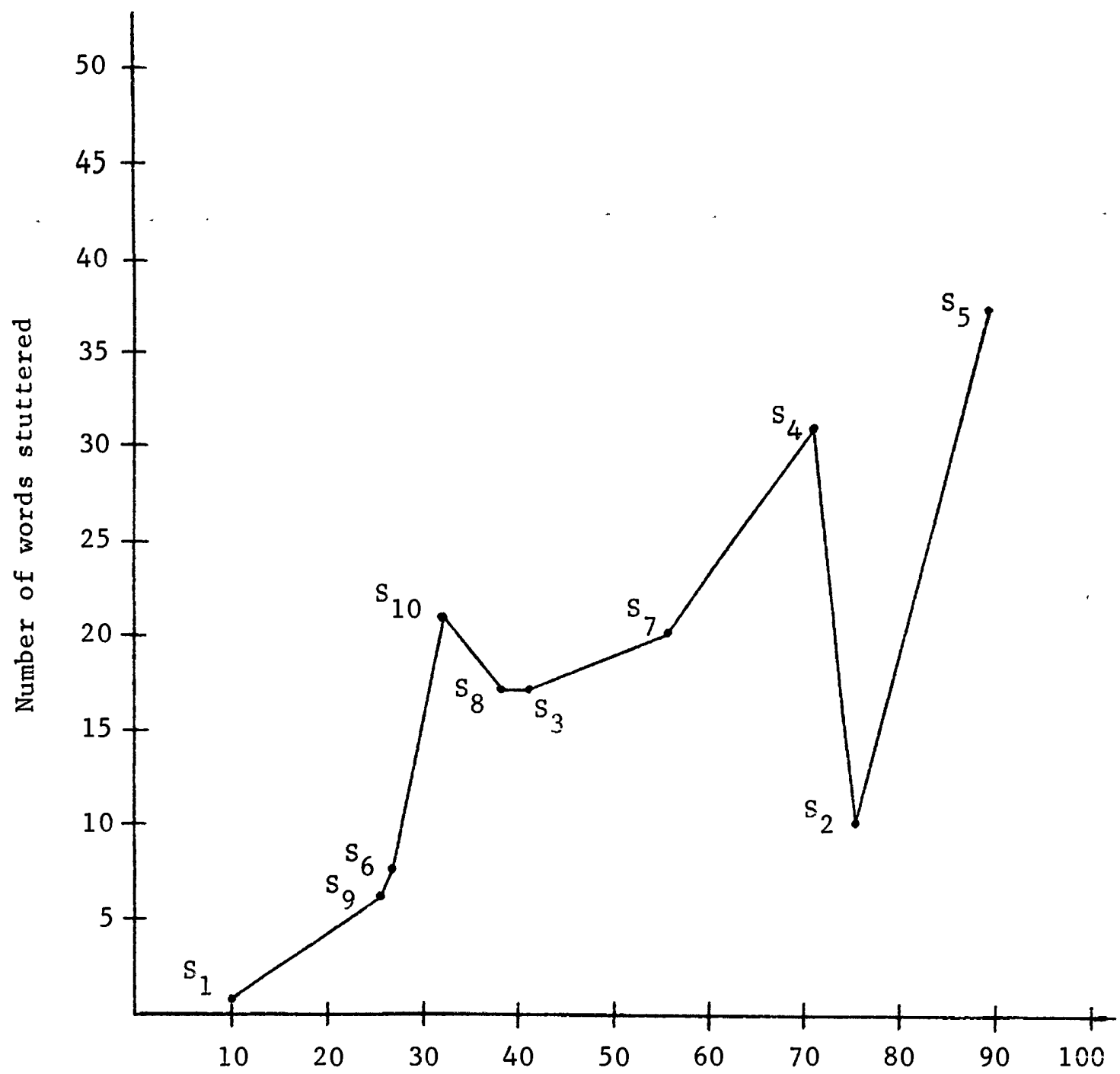

Percentage of accuracy of predicting stuttering

Figure 10. Using Pearson's product-moment coefficient of correlation method, a high correlation $(+0.77)$ was demonstrated between accuracy of prediction and the frequency of stuttering.

accuracy of prediction and the frequency of stuttering. In reviewing the literature concerning expectancy to stutter, no discussions in reference to the relationship between these two components of stuttering were found. The more one stuttered, the more accurate he was in predicting his stuttering. Conversely, the less one stuttered, the 
greater the error of prediction. Referring back to Table III, those subjects who were least accurate in predicting their stuttering (subjects 1,6 , and 9) expected to stutter much more often than they actually did. Those who were most accurate in predicting moments of stuttering (subjects 2,4 , and 5) stuttered on all or nearly all of their expectancy words. Once one acquires the reputation of being a stutterer, he will expect to stutter whether he does or not. Thus, expectancy to stutter as a maintenance factor is to be distinguished from the idea of expectancy as a precipitative or causal factor which this investigator does not support based on the data from the present study. It must be remembered stuttering is a behavior which progresses through a developmental sequence of four phases (Luper and Mulder 1964). Only in the last two phases, "confirmed" and "advanced" stuttering, is expectancy mentioned as a component of that behavior. Stuttering behavior begins before the person experiences any expectancy to stutter; therefore, expectancy could not be a causal or precipitative factor of stuttering.

Perhaps once stuttering behavior is established, expectation may serve as a "self-fulfilling hypothesis" which would explain why a significantly greater percentage of expectancy words are stuttered compared to the percentage of stuttered non-expectancy words. Expectancy may serve to maintain stuttering behavior which is already established.

Correlation Between Frequency of Stuttering and Expectancy to Stutter

The relationship between the frequency of stuttering and percentage of expectancy words is shown in Figure 11 . Subject 1 demon- 


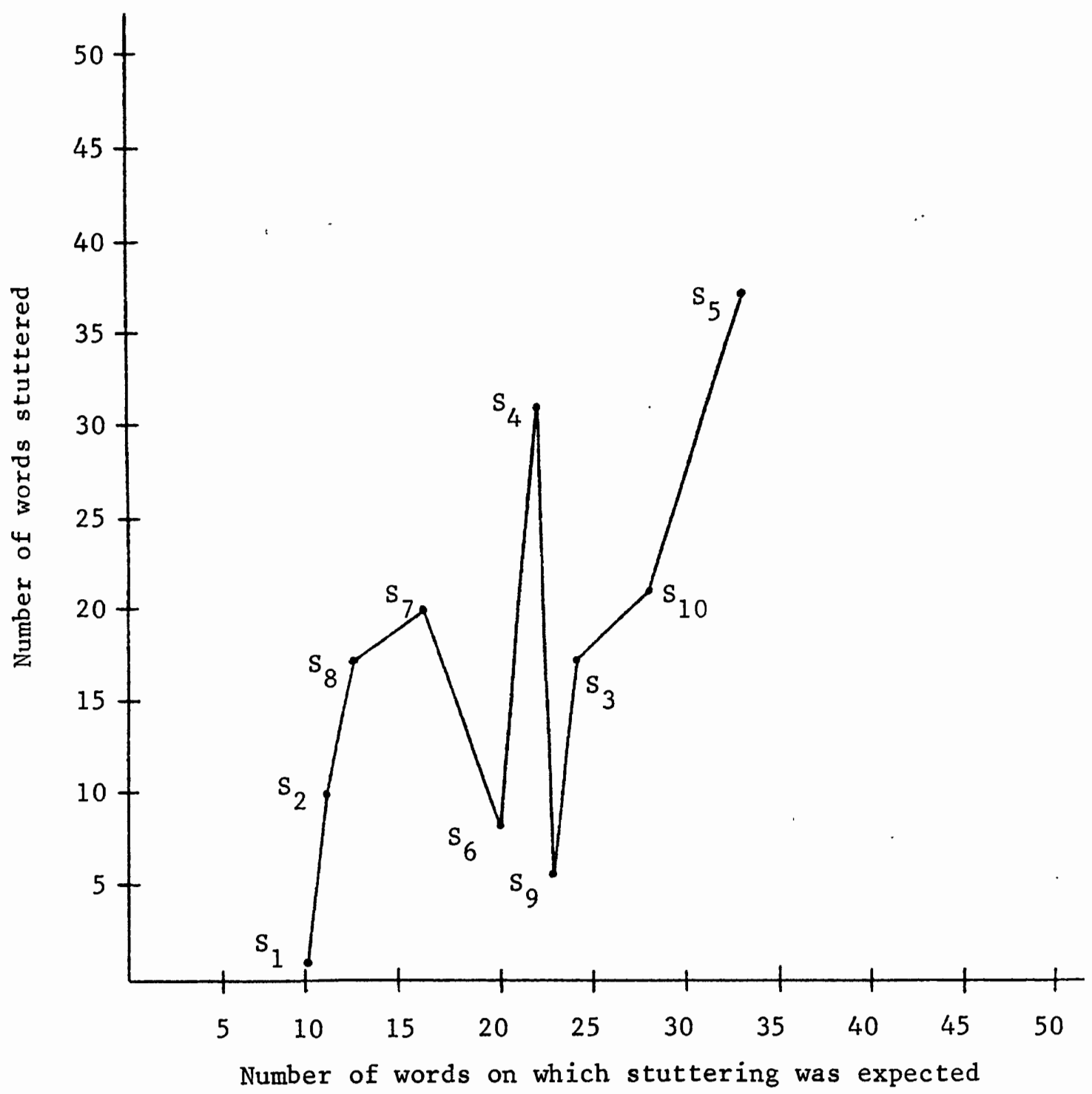

Figure 11. A moderate correlation of +0.65 was demonstrated between the number of words presented on which stuttering was expected and the number of words stuttered.

strated the least number of words stuttered (2 percent) and the lowest level of expectancy to stutter (20 percent). Subject 5 , who stuttered most frequently ( 74 percent), also demonstrated the highest frequency of expectancy (66 percent). Pearson's product-moment coefficient of correlation method revealed a moderate correlation $(+0.65)$ between 
frequency of stuttering and expectancy to stutter. Once one acquires the reputation of being a stutterer, he will expect to stutter which serves to maintain the already present stuttering behavior.

Further analysis of the data revealed those subjects who stuttered'more frequently stuttered on more words than the number they expected to stutter. On the other hand, subjects who stuttered less frequently predicted stuttering on more words than the number stuttered (see Table IV). Stated another way, the less. fluent speakers underpredicted their stuttering while the more fluent speakers overpredicted stuttering. The person who stutters less may not be better off than a more severe stutterer as he most likely expects to stutter more often than he does. Johnson (1957) once stated people who stutter live "lives of quiet desperation."

The high correlation between frequency of stuttering and expectancy is the basis for theories based on the anticipatory-struggle hypothesis. The basic assumption of this hypothesis is that all moments of stuttering are preceded by expectancy to stutter (Silverman and Williams 1972). Various theories based on this anticipatorystruggle hypothesis view stuttering as that which is done to avoid stuttering when stuttering is expected (Curlee and Perkins 1968). The more frequently stuttering is expected, the more frequently it occurs (Knott, Johnson, and Webster 1937; Soderberg 1967; Martin and Haroldson 1967; Curlee and Perkins 1968).

Based on results found in the review of the literature and the present study, this investigator supports the view that an increase in stuttering results in increased expectancy to stutter rather than 
expectancy causing or precipitating stuttering. It is hypothesized once this cycle is begun, expectancy then may serve as a factor which maintains stuttering behavior rather than causing it. This position is taken in view of the evidence which demonstrated accuracy of predicting stuttering is quite poor for most people who stutter (Johnson and Solomon 1937; Martin and Haroldson 1967; Silverman and Williams 1972), indicating expectancy does not precede all or even most moments of stuttering. Given the same data, two investigators may arrive at contradictory conclusions. For example, Johnson and Solomon (1937) interpreted their findings as indicative of expectancy as a precipitative factor of stuttering. However, accuracy of predicting stuttering for their study was quite low (24 to 39 percent) as calculated according to the procedure used in the present study.

Correlation Between Accuracy of Predicting Stuttering and Frequency of Stuttering

Figure 12 illustrates the relationship between accuracy of predicting stuttering and the percentage of words on which stuttering was expected for the ten subjects in the present study. Using Pearson's product-moment coefficient of correlation method, a low level of correlation $(+0.31)$ between accuracy of prediction and percentage of expectancy words was demonstrated. Frequency of expectancy did not appear to be related to accuracy of predicting stuttering for this group as a whole.

Summary

Results of the present study and discussion of those results 


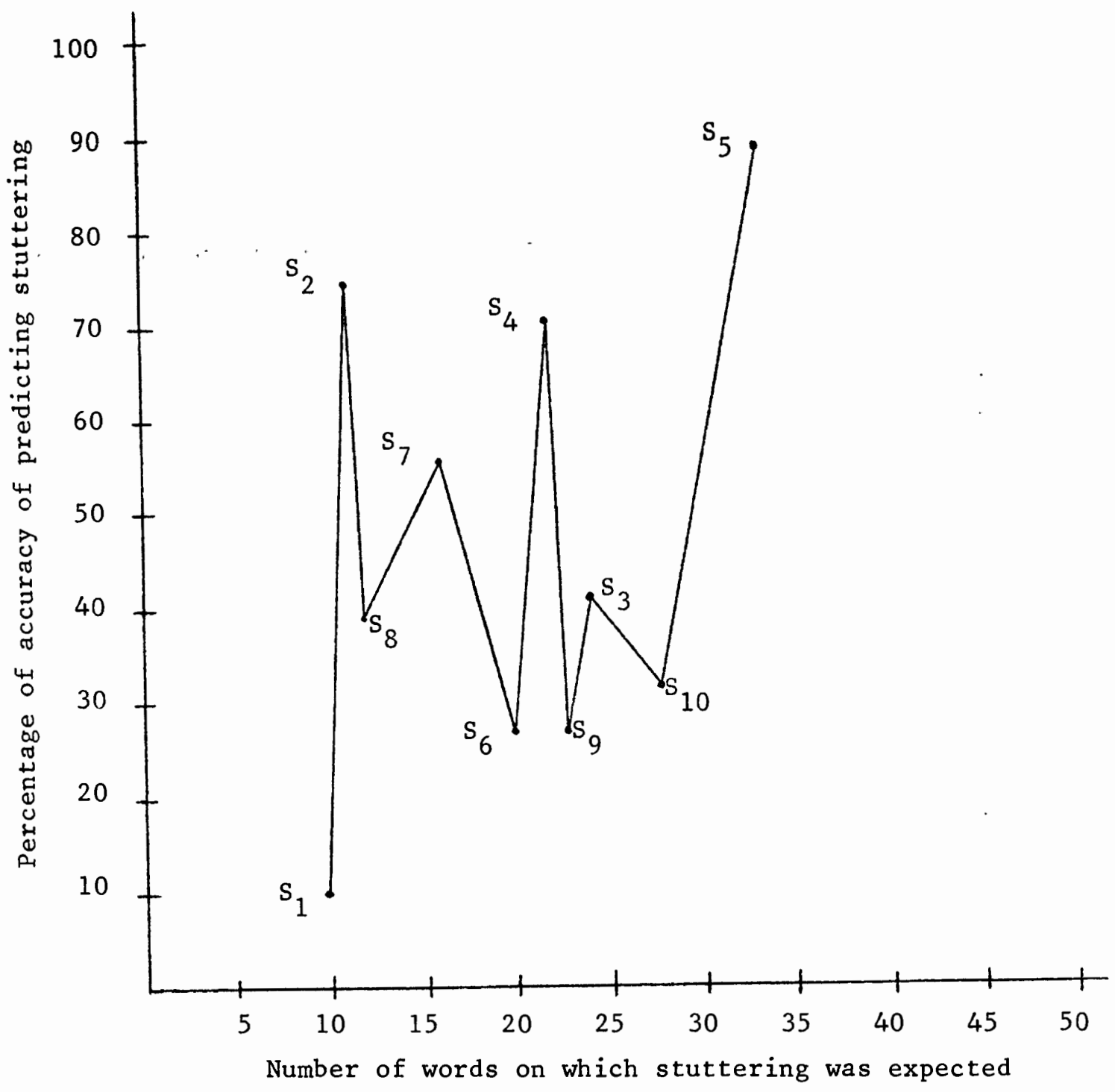

Figure 12. A low level of correlation $(+0.31)$ between accuracy of prediction and number of expectancy words was demonstrated.

were presented in this chapter. In summary, the results indicated signalled expectancy to stutter is not accompanied by a significant increase in muscle tension 3 seconds prior to speaking compared to signalled non-expectancy to stutter as measured by EMG. Further ana1ysis of data revealed accuracy of predicting stuttering ranged from 10 to 89 percent for individual subjects in this study with a mean of 49 
percent for the group. A very high correlation of +0.77 , indicating a very dependable relationship, was found for accuracy of prediction and frequency of stuttering. The more one stuttered, the more accurate he was in predicting his stuttering. On the other hand, the less one stuttered, the greater the error of prediction. The correlation between frequency of stuttering and percentage of expectancy words was moderate $(+0.65)$, indicating the more one stuttered, the more he expected to stutter. These results indicate expectancy to stutter maintains stuttering behavior rather than causes or precipitates stuttering. A low correlation of +0.31 was demonstrated for accuracy of prediction of stuttering and percentage of expectancy words, indicating frequency of expectancy does not affect accuracy of predicting stuttering. 
CHAPTER V

SUMMARY AND IMPLICATIONS

$\underline{\text { Summary }}$

Numerous studies have demonstrated the tension component of stuttering behavior; however, the relationship between muscle tension and the moment of signalled expectancy to stutter has not been investigated. Many theories of stuttering are based on the hypothesis that a11 moments of stuttering are preceded by expectancy to stutter. It also is held by many authorities on stuttering that expectancy is a precipitative, if not causal, factor of stuttering. If such is the case, one might expect to see the moment of signalled expectancy to stutter accompanied by an increase in muscle tension in the speech mechanism.

The purpose of this study was to determine what relationship (if any) exists between signalled expectancy to stutter and a significant increase in muscle action potential in adults as measured by electromyography (EMG).

The question posed in this study was: Is the moment of signalled expectancy to stutter accompanied by a significant increase in muscle tension compared to the moment of signalled non-expectancy to stutter as measured by EMG? In answer to this question, the present study demonstrated no significant increase in muscle tension during signalled expectancy to stutter. 
The subjects in this study included 9 male and 1 female stutterers ranging in age from 22 years to 50 years of age with a mean age of 32 years and 9 months.

This study took place in a $6^{\prime} \times 8^{\prime}$ shielded room containing a Grass electroencephalograph amplifier, Mode1 6B, with a built-in 8-channel polygraph recorder. Seven of the 8 channels were utilized for this study. Tin, dish-shaped electrodes were placed at 6 sites as follows: orbicularis oris; digastric muscle; slightly above the larynx; trapezius muscle; right earlobe (reference electrode); and center of the forehead (ground electrode). Muscle action potentials (MAPs) were recorded for the first 4 electrode sites.

Each subject was presented with 50 test words, one at a time. Before saying each word aloud, the subject indicated whether or not he expected to stutter when saying the word by pressing a button once for "yes" and twice for "no." After pressing the button, the subject was signalled to say the word.

Peak-to-peak measurements of muscle action potentials for 10 expectancy responses and 10 non-expectancy responses, selected at random, were taken for each of the subjects at each of the 4 electrode sites. Using a $\underline{t}$-test for related variables, 4 t-tests were applied, one to each set of MAP values of expectancy responses and nonexpectancy responses at each electrode site for the group as a whole. Statistical analysis revealed no significant increase in muscle tension during expectancy to stutter as compared to non-expectancy to stutter at the 0.05 leve1 $(p>0.05)$ of confidence. Resultant t-test scores were as follows: orbicularis oris, $\underline{t}=0.607$; digastric muscle, $\underline{t}=$ 
0.952 ; extrinsic laryngeal muscles, $\underline{t}=0.944$; and trapezius muscle, $\underline{t}=0.331$. At the 0.05 level of confidence $\underline{t}=2.26$ was required for significance.

Further analysis of the data revealed a high correlation of +0.77 between accuracy of prediction and the frequency of stuttering. The more one stuttered, the more accurate he was in predicting his stuttering. Conversely, the less one stuttered, the greater the error of prediction. Those subjects who were most accurate in predicting moments of stuttering stuttered on all or nearly all of their expectancy words. Those who were least accurate in predicting their stuttering expected to stutter much more often than they actually did.

The relationship between the frequency of stuttering and percentage of expectancy words demonstrated a moderate correlation of +0.65 . One possible interpretation is that once one acquires the reputation of being a stutterer, he will expect to stutter more, which may serve to maintain the already present stuttering behavior. The person who stutters less may not be better off than a more severe stutterer as he most likely expects to stutter more often than he does. Johnson (1957) stated stutterers live "lives of quiet desperation."

A low level of correlation $(+0.31)$ between accuracy of prediction and percentage of expectancy words was demonstrated. Frequency of expectancy did not appear to be related to accuracy of predicting stuttering. 


\section{Implications}

\section{Clinical}

The foremost implication of this study is stuttering behavior is not a result of expectancy to stutter as proponents of the anticipatory-struggle hypothesis argue. Therefore, it might not be appropriate for a clinician to inform a client he stutters because he expects to stutter. However, it could be appropriate to tell the client he expects to stutter because he has established a pattern of stuttering in the past, and expectancy to stutter may serve to maintain that behavior which is already established.

In order to eradicate expectancy to stutter, the pattern of stuttering behavior must first be eliminated. Most children who stutter do not carry this behavior over into adulthood. Most adult stutterers, however, will need clinical intervention to learn how they are interfering with their speech and how they can speak fluently.

\section{Future Research}

Due to the nature and complexity of the present study, it is highly recommended similar studies performed in the future be conducted by investigators having a strong background in anatomy, neurology, and electronics, as well as resource persons in the field of neurology. Access to the most modern EMG equipment and technology is recommended to obtain data which can be integrated, cataloged, and analyzed by a computer using digital readouts.

More research is needed in the area of muscle tension as it relates to stuttering, and more specifically as it relates to 
expectancy to stutter. This investigator recommends the use of needle electrodes in future studies to obtain more localized MAPs which are less likely to be obscured or contaminated by activity of neighboring muscle groups.

A future study along the line of the present study is recommended with appropriate modifications. Additional information might be gained if all subjects were administered the Stuttering Severity Instrument (SSI) prior to the test situation in order to have an objective measure of each person's stuttering behavior. Presentation of individual words did not appear to pose much difficulty for many subjects. In order to obtain a greater sample of speech with which to work, sentences could be presented in order to obtain enough expectancy responses for analysis.

It would be interesting to have subjects fill out a questionnaire after presenting fifty or more words or sentences to see if they have a level of awareness as to their cues for expectancy to stutter. Following completion of the questionnaire, an additional fifty words or sentences would be presented, and pre- and post-questionnaire performance evaluated.

In addition to the 4 electrode sites monitored in the present study, it is recommended the masseter muscle be monitored. The moment and duration of the MAP responses selected for analysis might be varied. Rather than selecting a 1-second time frame approximately 3 seconds prior to speaking, perhaps a time frame beginning 3 seconds prior to the beginning of the speech utterance through the moment at which the utterance begins could be analyzed, integrating and averag- 
ing the MAPs for comparison. Breaking such a 3-second period into smaller time frames might reveal at what point in the dynamic speech process muscle tension increases beyond normal limits, resulting in stuttering .

A more efficient and reliable means of signalling expectancy and non-expectancy to stutter would be helpful. Rather than pressing the same button once for "yes" and twice for "no," perhaps having two buttons on a panel with one marked "yes" and the other "no" would enable the subject to respond with greater speed and accuracy. 


\section{BIBLIOGRAPHY}

ADAMS, M. R., Some common problems in the design and conduct of experiments in stuttering. J. Speech Hearing Dis., 41:3-9 (1976).

BAR, A., SINGER, J., and FELDMAN, R. G., Subvocal muscle activity during stuttering and fluent speech: A comparison. J. South African Logopedic Soc., $16: 9-14$ as cited in 0. Bloodstein, Stuttering as tension and fragmentation, in J. Eisenson (ed.), Stuttering: A Second Symposium, New York: Harper and Row (1975).

BLOODSTEIN, 0., The development of stuttering: I. Changes in nine basic features. J. Speech Hearing Dis., 25:219-37 (1960a).

BLOODSTEIN, 0., The development of stuttering: II. Developmenta1 phases. J. Speech Hearing Dis., 25:366-76 (1960b).

BLOODSTEIN, 0., The development of stuttering: III. Theoretical and clinical implications. J. Speech Hearing Dis., 26:67-81 (1961).

BLOODSTEIN, O., Stuttering as tension and fragmentation. In J. Eisenson (ed.), Stuttering: A Second Symposium, New York: Harper and Row (1975).

BROWN, S. F., The loci of stutterings in the speech sequence. J. Speech Dis., 10:181-92 (1945).

BROWN, S. F., CURTIS, J. F., EDNEY, C. W., JOHNSON, W., and KEASTER, J., Speech Handicapped School Children (revised edition). New York: Harper (1956) as cited in Silverman, F. H., and Williams, D. E., Prediction of stuttering by school-age stutterers. J. Speech Hearing Res., 15:189-93 (1972).

BRUTTEN, E. J., Palmar sweat investigation of disfluency and expectancy adaptation. J. Speech Hearing Res., 6:40-8 (1963).

CURLEE, R. F., and PERKINS, W. H., The effect of punishment of expectancy to stutter on the frequencies of subsequent expectancies and stuttering. J. Speech Hearing Res., 11:787-95 (1968).

DANIEL, B., and GUITAR, B., EMG feedback and recovery of facial and speech gestures following neural anastomosis. J. Speech Hearing Dis., 43:3-8 (1978). 
FREEMAN, F. J., and USHIJIMA, T., Laryngeal muscle activity during stuttering. J. Speech Hearing Res., 21:538-62 (1978).

GRASS MEDICAL INSTRUMENTS, Grass Mode1 8 Instruction Manual: Part I: Operation. Quincy, Mass. (1974).

GUITAR, B., Reduction of stuttering frequency using analog electromyographic feedback. J. Speech Hearing Res., 18:672-85 (1975).

HAMRE, C. E., and WINGATE, M. E., Stuttering consistency in varied contexts. J. Speech Hearing Res., 16:238-47 (1973).

HIROSE, H., Electromyography of the articulatory muscles: Current instrumentation and technique. Haskins Lab. Status Rep. Speech Res., SR 25/26, 73-86 (1971).

JOHNSON, W., Understanding the needs of the speech handicapped child. Summary of Proceedings: 9th Annual In-Service Conference on Exceptiona1 Children. State Dept. of Ed., Salem, Oregon, May 17 and 18, 1957. (P. 13)

JOHNSON, W., and AINSWORTH, S., Studies in the psychology of stuttering: $X$. Constancy of loci of expectancy of stuttering. J. Speech Dis., 3:101 (1938).

JOHNSON, W., and KNOTT, J. R., Studies in the psychology of stuttering: $I$. The distribution of moments of stuttering in successive readings of the same material. J. Speech Dis., 2:17-9 (1937).

JOHNSON, W., LARSON, R. P., and KNOTT, J. R., Studies in the psychology of stuttering: III. Certain objective cues related to the precipitation of the moment of stuttering. J. Speech Dis., 3:23-5 (1937).

JOHNSON, W., and MILLSAPPS, L. S., Studies in the psychology of stuttering: VI. The role of cues representative of past stuttering in the distribution of stuttering moments during oral reading. J. Speech Dis., 2:101-4 (1937).

JOHNSON, W., and SINN, A., Studies in the psychology of stuttering: V. Frequency of stuttering with expectation of stuttering contro1led. J. Speech Dis., 2:98-100 (1937).

JOHNSON, W., and SOLOMON, A., Studies in the psychology of stuttering: IV. A quantitative study of expectation of stuttering as a process involving a low degree of consciousness. J. Speech Dis., 2:95-7 (1937).

KNOTT, J. R., JOHNSON, W., and WEBSTER, M. J., Studies in the psycho1ogy of stuttering: II. A quantitative evaluation of expectation of stuttering in relation to the occurrence of stuttering. J. Speech Dis., 2:20-5 (1937). 
LANGE, J. I., The effects of low, moderate and high self-disclosure on electromyographic, psychogalvanic, and attitudinal response. Unpublished Masters thesis, Portland State University, Portland, Oregon (1975).

LUPER, H. L., and MULDER, R. L., Stuttering: Therapy for Children. Englewood Cliffs, N.J.: Prentice-Hall, Inc. (1964).

MARTIN. R. R., and HAROLDSON, S. K., The relationship between anticipation and consistency of stuttered words. J. Speech Hearing Res., 10:323-7 (1967).

MCLEAN, M., Variation in perioral reflex amplitude prior to lip muscle contraction for speech. J. Speech Hearing Res., 21:276-84 (1978).

MILISEN, R., Frequency of stuttering with anticipation of stuttering controlled. J. Speech Dis., 3:207-14 (1938).

MOON, B. S., An electromyographic comparison of muscle action potential of listeners presented time-compressed and normal speech stimuli. Unpublished Masters thesis, Portland State University, Portland, Oregon (1970).

PROSEK, R. A., MONTGOMERY, A. A., WALDEN, B. E., and SCHWARTZ, D. M., EMG biofeedback in the treatment of hyperfunctional voice disorders. J. Speech Hearing Dis., 43:282-94 (1978).

ROSSO, L. J., and ADAMS, M. R., A study of the relationship between the latency and consistency of stuttering. J. Speech Hearing Res., $12: 389-93$ (1969).

ROTH, J., M.D., Portland, Oregon. Personal interview, October 1978.

SEIDEL, A., WEINSTEIN, R. B., and BLOODSTEIN, O., The effect of interposed conditions on the consistency of stuttering. J. Speech Hearing Res., 16:62-6 (1973).

SHEEHAN, J. G., and VOAS, R. B., Tension patterns during stuttering in relation to conflict, anxiety-binding, and reinforcement. Speech Monographs, 21:272-9 (1954).

SILVERMAN, F. H., and WILLIAMS, D. E., Prediction of stuttering by school-age stutterers. J. Speech Hearing Res., 15:189-93 (1972).

SODERBERG, G. A., Linguistic factors in stuttering. J. Speech Hearing Res., 10:801-10 (1967).

STEFANKIEWICZ, S. P., and BLOODSTEIN, 0., The effect of a four-week interval on the consistency of stuttering. J. Speech Hearing Res., 17:141-5 (1974). 
VAN RIPER, C., Study of the thoracic breathing of stutterers during expectancy and occurrence of stuttering spasm. J. Speech Dis., $1: 61-72$ (1936).

VAN RIPER, C., The preparatory set in stuttering. J. Speech Dis., $2: 149-54$ (1937).

VAN RIPER, C., The Nature of Stuttering. Englewood Cliffs, N.J.: Prentice-Ha11 (1971).

WILLIAMS; D. E., SILVERMAN, F. H., and KOOLS, J. A., Disfluency behavior of elementary-school stutterers and nonstutterers: The consistency effect. J. Speech Hearing Res., 12:301-7 (1969).

WINGATE, M. E., Expectancy as basically a short-term process. J. Speech Hearing Res., 18:31-42 (1975). 
APPENDIX A

LETTER SENT TO SUBJECTS

Miss Cathy Miller

Speech \& Hearing Sciences

Neuberger Hall, Rm. 69

Portland State University

P. 0. Box 751

Portland, Oregon 97207

Dear

Thank you for your willingness to participate in my thesis study at the University of Oregon Medical School. Enclosed is a map of the $U$ of 0 Medical School campus, a description of the study procedures, and a release form. Please complete the release form and return it to me when we meet to run the study.

I will arrange an appointment for you at p.m. on Plan for the actual running of the study to take about $1 \frac{1}{2} \overline{\text { hours. You }}$ may want to bring a book or magazine to read in case our appointment time is delayed. This may or may not occur as we are using hospital equipment, and emergency cases have priority use of this equipment.

If for any reason you need to contact me, I can be reached at 646-0615 (home) or 229-3602 (school-message). The phone number for the EEG/EMG lab where the study will take place is $225-8117$ or $225-8118$.

Thank you again for your interest and participation.

Sincerely,

Cathy Miller

Graduate Student 


\section{APPENDIX B}

\section{EXPERIMENTAL PROCEDURE}

This study will take place in the EEG/EMG Laboratory located on ha11way 9-C in the University of Oregon Medical School Hospital South.

1. You will be shown to the room in which the study will take place.

2. You will be seated in a chair in this room with the investigator.

3. The investigator will apply the six surface electrodes in the following manner:

a) The sites of the electrodes will be: 1) near the right corner of the mouth; 2) under the chin; 3) slightly above the voice box (1arynx); 4) on the back of the neck; 5) on the forehead; and 6 ) on the right ear lobe.

b) Each electrode will be placed in the proper position and adhesive jelly will be applied to the electrode and surrounding skin.

c) An air jet will be used to dry the adhesive jelly.

d) A very blunt needle will be used to abrade the surface of the skin under each electrode (this may or may not cause slight discomfort), and a drop of saline solution will be placed in each electrode.

e) After the test, the electrodes will be removed by a solution which dissolves the adhesive jelly.

f) There is no electrical shock involved in this study!

4. After the electrodes have been positioned properly, you will be presented with printed words and asked to read each word out loud and indicate your expectancy or non-expectancy to stutter upon saying each word.

5. Your participation is greatly appreciated. Thank you! 


\section{APPENDIX C}

\section{HUMAN SUBJECT RELEASE FORM}

I, freely offer myself as a subject for an empirical study under the sponsorship of the Portland State University Speech and Hearing Sciences Department. I have been informed to my satisfaction about the procedures of the study, and I understand any information regarding my performance or information about myself which I provide will be treated confidentially, and publication of such information will conceal my identity.

If subject is under 18 years of age, this release must be countersigned by a parent or authorized guardian. Speech \& Hearing Sciences Dept. Portland State University $\mathrm{NH} 69$ P. 0. Box 751 


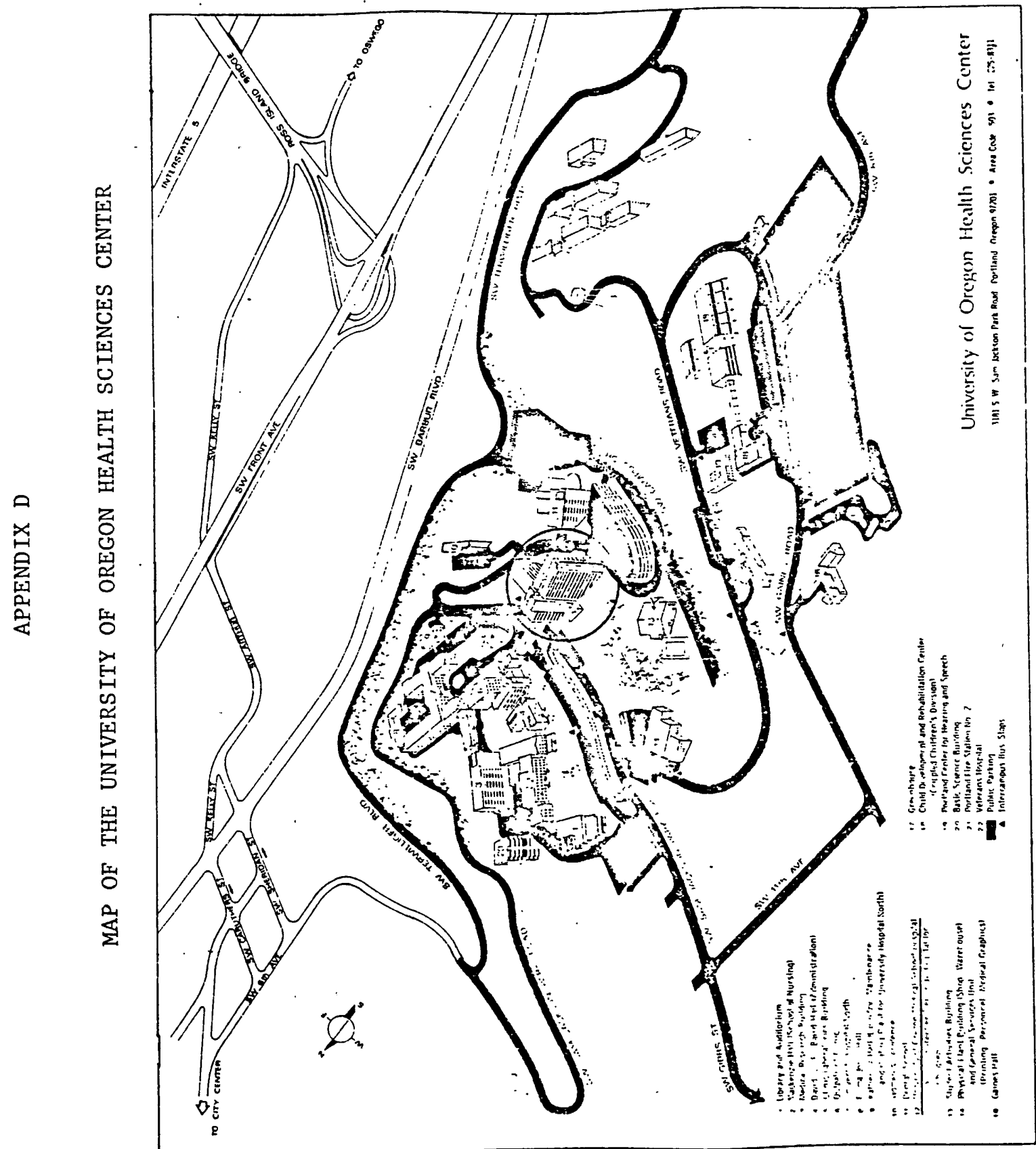


APPENDIX E

LIST OF STIMULUS WORDS

\section{Practice words:}

1. vanilla

2. gasoline

3. fingerprint

4. Democrat

5. battleship

Test words:

1. package

2. kangaroo

3. whisper

4. difficult

5. hamburger

6. officer

7. stomach

8. elephant

9. blackberry

10. newspaper

11. passengers

12. eleven
13. accident

14. children

15. remember

16. Methodist

17. horrible

18. Pacific

19. airplane

20. magic

21. condition

22. birthday

23. typewriter

24. lovingly

25. automobile

26. thickening

27. basket

28. afternoon

29. jingle

30. hockey

31. bicycle
32. music

33. telephone

34. radio

35. ketchup

36. pineapple

37. mustard

38. tomato

39. dictionary

40. good-bye

41. satellite

42. envelope

43. personal

44. Indian

45. anima 1

46. Thanksgiving

47. natural

48. Mother

49. unscramble

50. liberty 
APPENDIX $F$

DATA COLLECTION SHEET

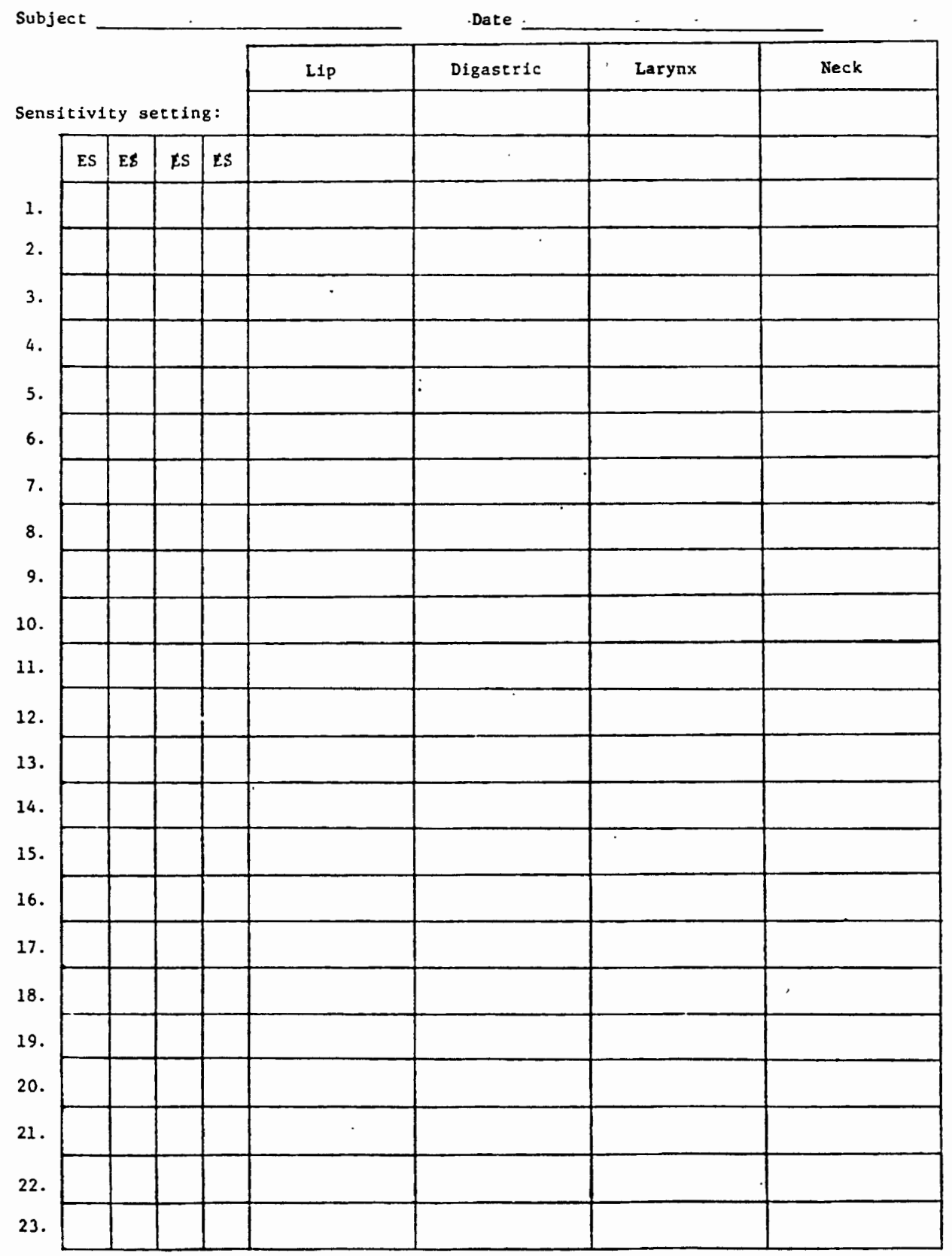




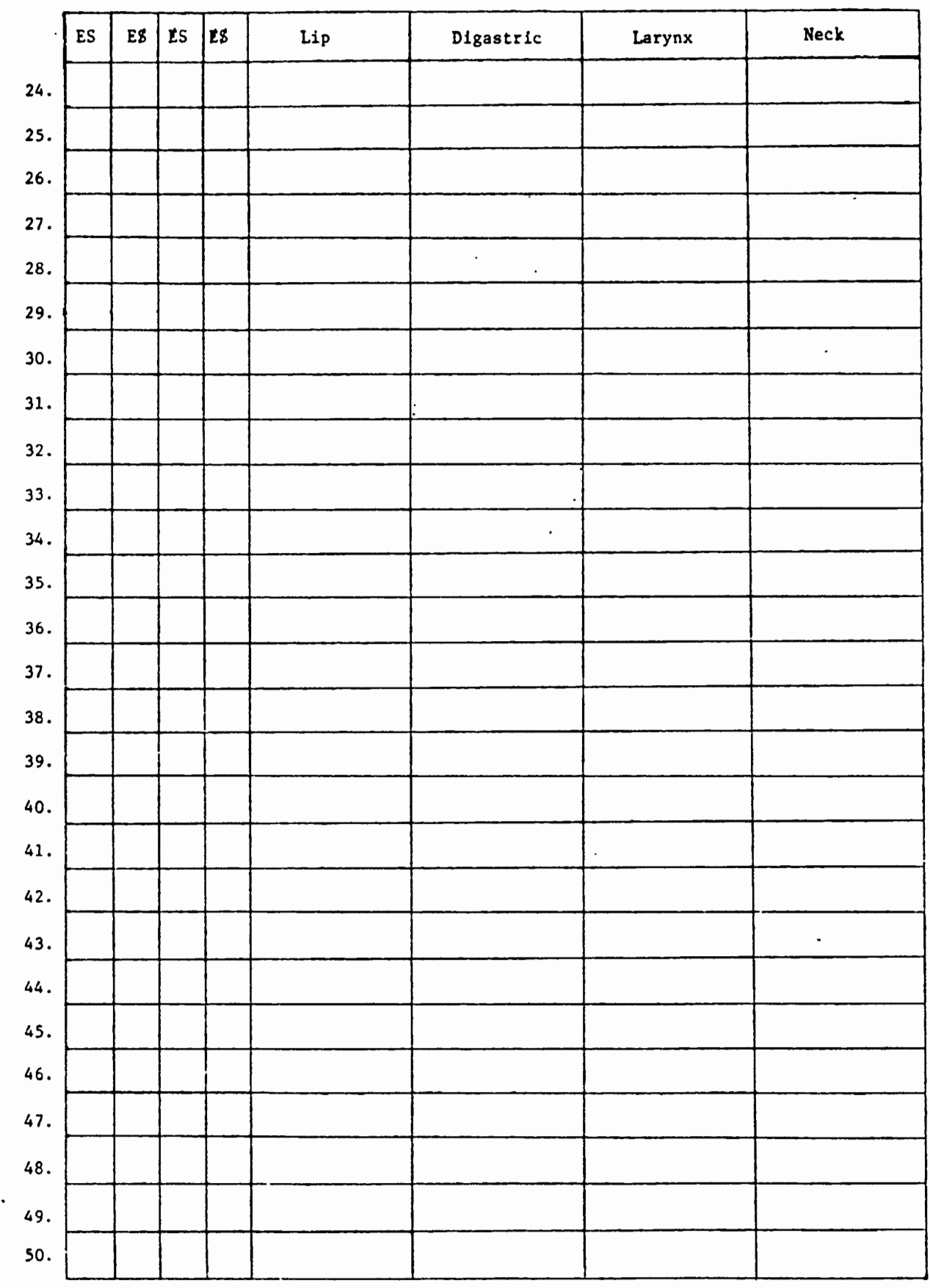




\section{APPENDIX G}

\section{ACCURACY OF PREDICTING STUTTERING USING DATA OBTAINED IN PREVIOUS STUDIES}

Figures in the grids below are percentages of the total number of words presented. Accuracy of predicting stuttering was calculated using the ES, E\$, and $\# S$ responses.

All of the grids show a high percentage of responses in the "no expectancy followed by no stuttering" ( $\$ \$$ ) category. People who stutter do so on only a small portion of words. Most of their words are spoken fluently.

Johnson and Solomon (1937):

Reading 1: (Subjects marked expectancy words 15 minutes before reading.)

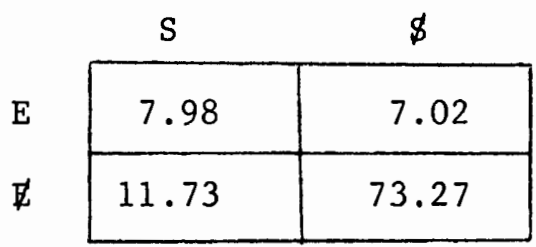

$\mathrm{N}=13$

Accuracy of prediction, $30 \%$

Reading 2: (Same conditions as reading 1)

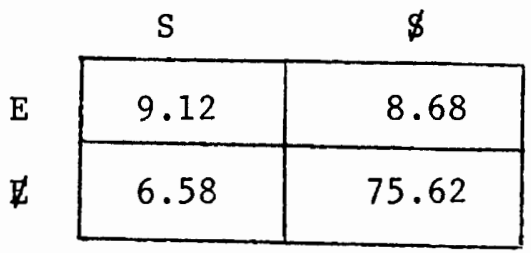

$\mathrm{N}=13$

Accuracy of prediction, $37 \%$

Reading 3: (Subjects marked expectancy words 1 to 7 days before reading.)

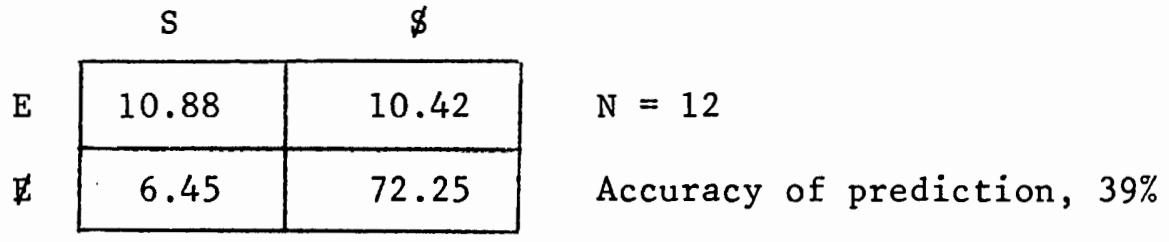


Reading 4: (Subjects marked expectancy words 15 minutes before reading while being recorded.)

\begin{tabular}{|c|c|c|}
\hline & $S$ & $\$$ \\
\hline & 4.12 & 5.54 \\
\hline & 7.22 & 83.11 \\
\hline
\end{tabular}

$\mathrm{N}=10$

Accuracy of prediction, $24 \%$

Knott, Johnson, and Webster (1937):

(1) Definitely expect to stutter

(2) Doubtfully expect to stutter

(3) Definitely do not expect to stutter

Clinical Group: (Subjects who have received speech therapy intervention)

\begin{tabular}{|c|c|c|c|}
\hline & $S$ & $\$$ & \\
\hline$E(1)$ & 1.93 & 0.13 & $N=12$ \\
\hline$\not(3)$ & 0.38 & 96.35 & $\begin{array}{l}\text { Accuracy of prediction, } \\
79 \%\end{array}$ \\
\hline
\end{tabular}

Non-Clinical Group: (Subjects who did not receive speech therapy intervention)

\begin{tabular}{l|c|c|}
\multicolumn{1}{c}{ E (1) } & \multicolumn{1}{c}{$S$} & \multicolumn{1}{c}{$\$$} \\
\cline { 2 - 3 } & 27.12 & 1.12 \\
\hline Z (3) & 2.00 & 64.46 \\
\hline
\end{tabular}

$\mathrm{N}=10$

Accuracy of prediction, $89 \%$

Martin and Haroldson (1967):

(1) Definitely will not stutter

(2) Probably will not stutter

(3) Might stutter

(4) Probably will stutter

(5) Definitely will stutter

\begin{tabular}{|c|c|c|c|}
\hline & S & $\$$ & \\
\hline$E(5)$ & 1.01 & 1.33 & $\mathrm{~N}=30$ \\
\hline$\not Z(1)$ & 6.83 & 90.83 & $\begin{array}{l}\text { Accuracy of prediction, } \\
11 \%\end{array}$ \\
\hline
\end{tabular}




\begin{tabular}{|c|c|c|c|}
\hline & S & $\$$ & \\
\hline$E(4,5)$ & 3.85 & 6.00 & $\mathrm{~N}=30$ \\
\hline$\not \mathcal{E}(1,2)$ & 6.87 & 70.29 & $\begin{array}{l}\text { Accuracy of prediction, } \\
23 \%\end{array}$ \\
\hline
\end{tabular}

Silverman and Williams (1972):

Subjects 8 to 9 years of age:

\begin{tabular}{|l|l|}
\hline \multicolumn{1}{c}{$\mathrm{S}$} & \multicolumn{1}{c}{$\$$} \\
\hline \multirow{2}{*}{2.92} & 1.54 \\
\hline 6.46 & 89.08 \\
\hline
\end{tabular}

$\mathrm{N}=13$

Accuracy of prediction, $27 \%$

Subjects 10 to 11 years of age:

\begin{tabular}{|c|c|}
\hline \multirow{2}{*}{$E$} & \multicolumn{1}{c}{$S$} \\
\hline \multirow{2}{*}{8.25} & 2.37 \\
\hline 6.38 & 83.00 \\
\hline
\end{tabular}

$\mathrm{N}=16$

Accuracy of prediction, $49 \%$

Subjects 12 to 13 years of age:

\begin{tabular}{|c|c|}
\multicolumn{1}{c}{$\mathrm{S}$} & \multicolumn{2}{c}{$\$$} \\
\cline { 2 - 3 } & \multicolumn{1}{c}{$\$$} \\
\hline 4.89 & 3.22 \\
\hline 6.78 & 85.11 \\
\hline
\end{tabular}

$\mathrm{N}=18$

Accuracy of prediction, $33 \%$

Subjects 14 to 16 years of age:

\begin{tabular}{|c|c|c|}
\hline & $S$ & $\$$ \\
\hline$E$ & 24.75 & 6.13 \\
\hline 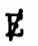 & 15.62 & 53.50 \\
\hline
\end{tabular}

$N=16$

Accuracy of prediction, 53\% 